\title{
FUNDAMENTAL STUDIES ON STEREOTAXIC SURGERY
}

\author{
Keizo Matsumoto, M.D. \\ Dept. of Neurological Surgery \\ (Director: Prof. Dr. D. Jinnai) \\ Okayama University Medical School
}

\section{INTRODUCTION}

The stereotaxic surgery is the best available method to produce a localized lesion in subcortical region which can be reached by using a special apparatus, providing that the position of subcortical nuclei, the target, is measured anatomically and statistically to produce the maximum lesion upon the target with minimum incidental tissue destruction.

The electroencephalographical researches on the subcortical nuclei and the electric stimulation of them have already been made by this method. ${ }^{1-5)}$ And the most remarkable clinical result has been obtained in the treatment of extrapyramidal disorders by this method. ${ }^{6-10)}$

\section{TABLE 1.}

Cortical operations

Removal of the cortical motor areas (Frazier)

Undercutting of the corresponding cortical field (Payr)

Premotor cortical resection (Klemme)

Cutting between areas 4 and $4 \mathrm{~s}$ (Meyers)

Capsular operations

Extirpation of the head of the caudate nucleus (Meyers)

Interruption of the pallidofugal fibers (Meyers)

Interruption of the anterior limb of the internal capsule (Browder)

Cerebral pedunculotomy (Walker)

Spinal operations

Posterior root section (Winslow and Spear)

Dorsal rhizotomy (Pollock and Davis)

Section of the posterior columns (Puusepp)

Anterolateral chordotomy (Foerster)

Pyramidotomy (Putnam, Oliver and Ebin)

Miscellaneous procedures

Damaging the dentate nucleus (Delmas-Marsalet und van Bogaert)

Prefrontal lobotomy (Rao and Morea)

Occlusion of the anterior choroidal artery (Cooper and Browder) 
Numerous methods of the operation for the extrapyramidal diseases were tried in the past (Table 1), but the effects of these methods were not still satisfactory. Moreover, these produced sometimes unpleasant complications and danger against the patient's life, so that no great expectation could be placed on these methods.

It is by the stereotaxic method that the neurosurgeon's dream for more effective operation with less lesion has been realized by degrees. And it may safely be said that, after all, with the advent of the stereotaxic method the operation for extrapyramidal disorders has become possible without any danger of accompanying complications.

This operation, however, has only taken its first stride forwards. Hereafter, the further improvement on the technique of operation, physiological and pathological study on subcortical nuclei and results of surgery for extrapyramidal disease are still the problems of future studies, and yet there is bright prospect in this field.

Jinnai, Nishimoto, Umeda and the author in our neuro-surgical clinic have already devised a precise apparatus (stereoencephalotome) following our own clinical experiences, and discussed the problems that the position of the effective destructive lesion to some of extrapyramidal disorders such as parkinsonism and choreoathetosis should be determined exactly; its target should be exactly reached by a proper method of destroying and how its destruction should be made on the precisely selected point (Fig. 1). ${ }^{11)}$ Moreover, though good results have been clinically obtained, much more adequate device and investigation to essential and fundamental problems of stereotaxic surgery have to be made in order to approach the target more precisely, and these points are explained in the present paper.

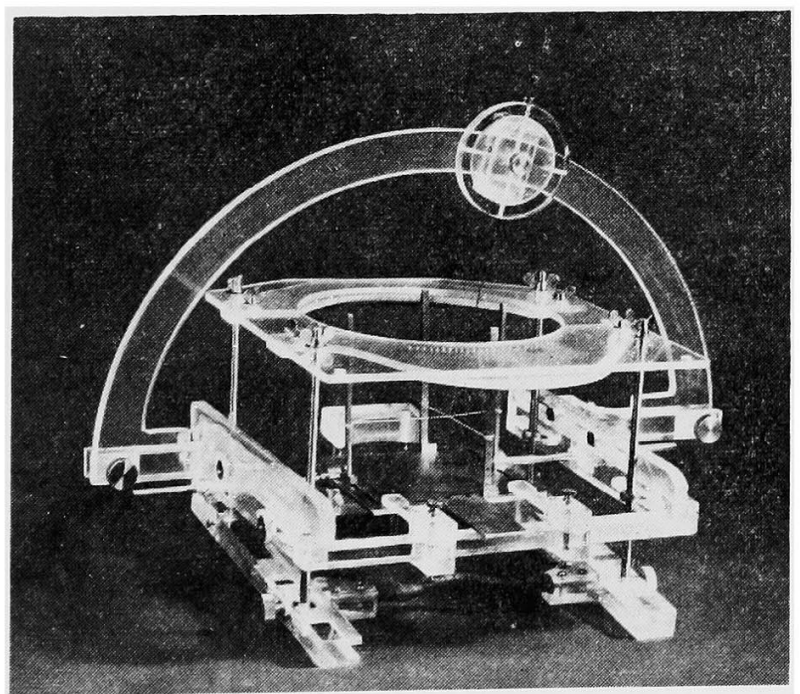

Fig. 1. Stereotaxic Apparatus, Model IV (Stereoencephalotome). 


\section{Part 1: The instrument for correcting distortion in the cranial roentgenogram}

\section{Significance of the Cranial Roentgenogram}

The stereotaxic apparatus for animals was devised and introduced by Horsley and Clarke in 1908.12) It may be well known that the apparatus by Horsley and Clarke has greatly contributed to researches for the physiology and the antomy of the brain as one of the most profitable experiments in animals.

The operation with the same idea and apparatus as in the case of animals had not been realized in human because of wide individual variations in the size and configuration of the human skull and with no room for the excuse of failure in operation. So the hope of Horsley and Clarke was not realized until 1947 when Spiegel et al. devised the first human apparatus. ${ }^{13)}$ And they succeeded in finding the relation between the skull and subcortical nuclei by using pneumoencephalography for the anatomical researches. Namely, they established a coordinate system of the structure within the brain with respect to visible parts in roentgenogram (pineal body, posterior and anterior commissures).

It proves to be a profitable method having less average error that the position of target can be calculated on the basis of the structure within the brain near the subcortical nuclei. Since then, under the same idea neurosurgeons all over the world have devised their own apparatus to perform the operation more precisely and easily, and thus various new types of the apparatus have come to yield more fruitful results. ${ }^{14-30)}$

The stereotaxic method, therefore, usually demands roentgenographical aid or control to decide the position of the target (subcortical nuclei), expecting the operation by Fenelon et al. and Brion and Guiot in which they made directly electrocoagulation in ansa lenticularis without apparatus and roentgenogram. ${ }^{31-34)}$

The intracerebral reference points such as anterior commissure, foramen of Monro, massa intermedia, pineal body, posterior commissure and suprapineal recess, etc., all visible in roentgenogram are near the center within the brain, so they are projected variously on the film in accordance with the position of the head or the X-ray tube. Accordingly, the cranial roentgenogram for stereotaxic operation should be worthwhile measuring. It is like measuring without scale to calculate the position of target from the intracerebral reference point with roentgenogram, on which the point is projected in inconstant positions of the head and the X-ray tube. Consequently, the operation will not be precise, even if the calculation and the stereoencephalotome be exact.

\section{The Method of the Cranial Roentgenogram}

Like many other apparatus, our stereotaxic apparatus has three interseting planes as a coordinate system (Fig. 2). 

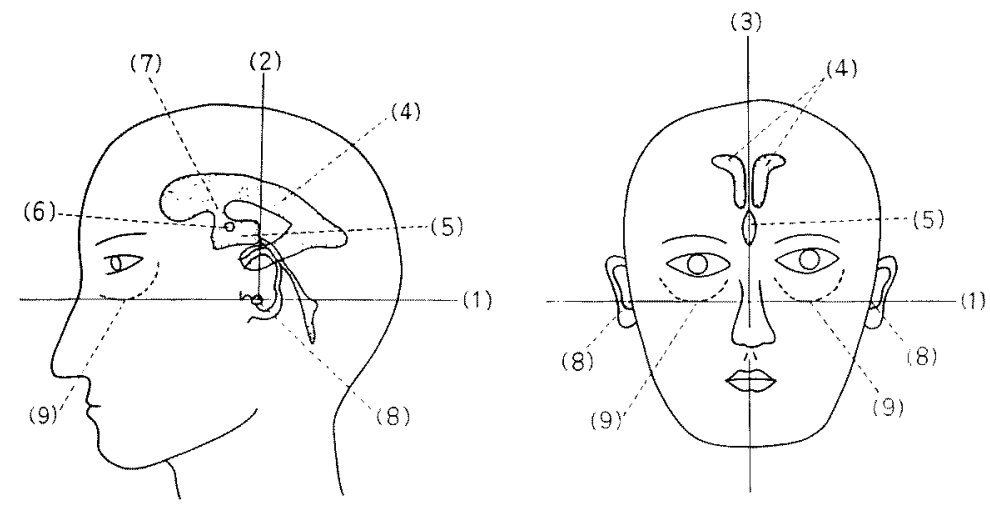

Fig. 2. Our stereotaxic coordinate system.

1) The horizontal base plane

6) The massa intermedia

2) The vertical base plane

7) The foramen of Monro

3) The mid-saggital plane

8) The external auditory pole

4) The lateral ventricle

9) The inferior ridge of orbit

5) The third ventricle

1) The horizontal base plane is determined by the bilateral inferior ridges of the orbit and external auditory meatus. 2) The vertical base plane is perpendicular to the horizontal plane and passes through the bilateral auditory meatus. 3) The mid-sagittal plane.

The foramen of Monro is selected as our intracerebral reference point in the pneumoencephalogram, and the site of the target is calculated by the position of the foramen of Monro in this coordinate.

The foramen of Monro is selected as our intracerebral reference point in the pneumoencephalogram, and the site of the target is calculated by the position of the foramen of Monro in this coordinate.

In taking lateral views (Fig. 3), the center line of X-ray should be in accord with the intersection of base planes (1) above-mentioned, and the plane of the film should be parallel to the base plane (3). That is to say, the line connecting bilateral auditory meatuses should fall on the focus of X-ray bulb and be perpendicular to the plane of the film.

In taking antero-posterior views (Fig. 3), the center line of $\mathrm{X}$-ray should be in accord with the intersection of base planes (1) and (3), and the plane of the film should parallel to the base plane (2). Namely, the line connecting the midpoint between bilateral external auditory meatus and the midpoint between bilateral inferior ridges of orbit should pass through the focus of $X$-ray tube and be perpendicular to the plane of the film.

Concerning the intracerebral reference point, as Narabayashi has already pointed out pneumoencephalographically, it is very difficult to visualize it clearly and exactly in all cases. He has once used Moljodoventriculography for the 


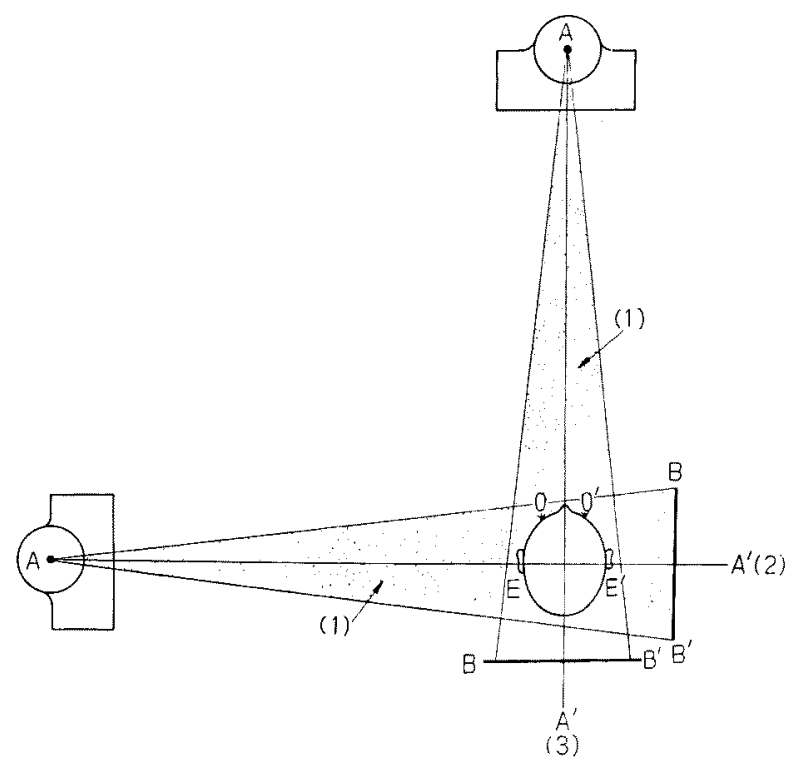

Fig. 3. The correct position of head in taking cranial roentgenogram by the instrument for correcting distortion, Model II.
A: the center of roentgen tube
(1) horizontal base plane
$\mathrm{AA}^{\prime}$ : the center line of $\mathrm{x}$-ray
(2) vertical base plane

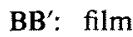
(3) mid-sagittal plane
$E E^{\prime}$ : external auditory meatus

OO': inferior ridge of orbit

solution of this problem despite of its unpleasant complication. But many neurosurgeons have adopted pneumoencephalography for this purpose, so there still remain many points to be improved technically.

The instruments for correcting distortion in the cranial roentgenogram, Model I and II were devised by the author. Model II is the instrument which was devised so that intracerebral reference point may be more clearly visualized than Model I. The lateral as well as antero-posterior views are taken with the patient's head in the brow-up position. Foramen of Monro is visualized easily and clearly if air exists within the ventricle, as air in the ventricle gathers rostrally by this position. The appearance of the reference point in the film will be mentioned in the next chapter.

All roentgenograms are taken in enlargement. The rate of enlargement is decided by the relative in the position of X-ray bulb, the patient's head and the plane of the film. In the instrument for correcting distortion, the picture is needed to be taken with constant distances of these three positions in both Model I and Model II, so the enlargement rate is constant. To indicate this enlargement rate more precisely in Model II, a metal scale $10 \mathrm{~cm}$ in length from tip to tip is applied 
to the vertical or sagittal plane which includes the target. (This is to be mentioned again later.)

When the cranial roentgenogram with this scale is taken, the enlargement rate of the plane including the target can be easily calculated.

Therefore, the lateral and antero-posterior cranial roentgenograms with clear intracerebral reference point (foramen of Monro) taken at a correct position of the head are measure-worthy to be available for the operation.

\section{The Use of the Instrument for Correcting Distortion in the Cranial Roentgenogram}

(1) Model I: In this instrument X-ray bulb and the film are placed in a constant position and the lateral and antero-posterior views are taken by changing the position and direction of the patient's head.

There are some shortcomings in Model I in that visualization of intracerebral reference point (foramen of Monro) is rather indistinguishable and so on. Therefore, the author devised a modified type, Model II, which is described as follows:

(2) Model II (Figs. 4 and 5): Model II consists of two parts of structures; a part for correcting distortion and its supporting table.

Structures for correcting distortion consist of the following parts as illustrated in Figs. 4 and 5 .

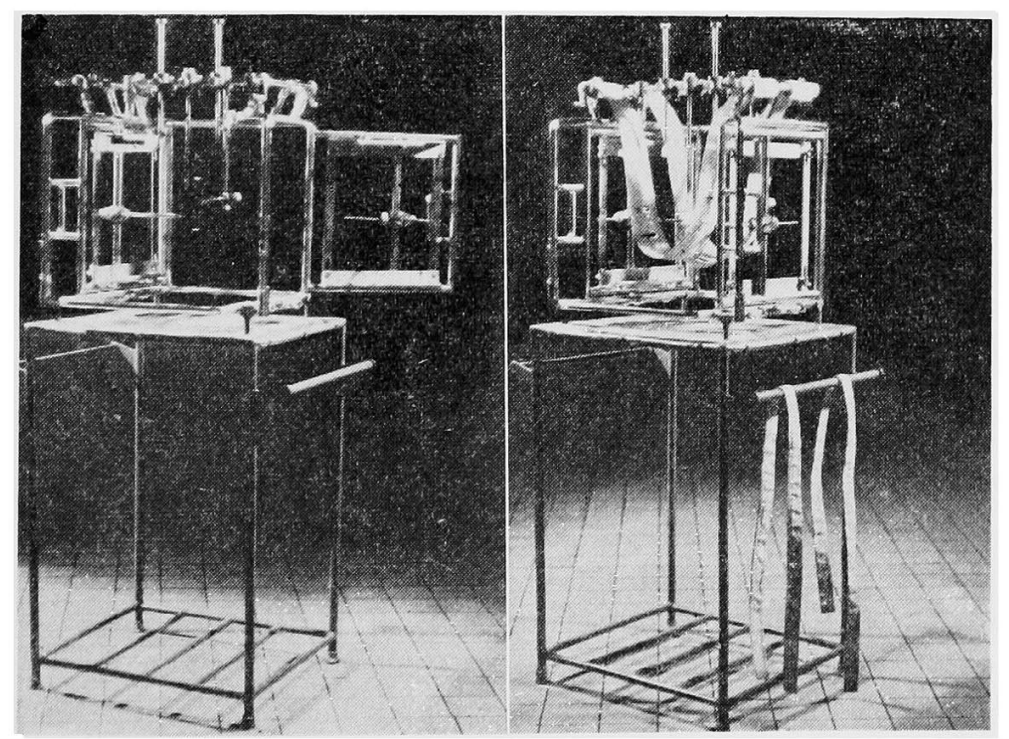

Fig. 4. The instrument without fixing belts.

Fig. 5. The instrument with fixing belts 
a) A pair of lower head fixing cotton belts with metal rollers. b) A pair of upper head-fixing cotton belts with metal stoppers. c) A pair of the door like frame with slide for cassette. d) A pair of metal poles indicating external auditory meatus. e) Transverse bar with a pair of poles indicating inferior ridge of orbits and a pole indicating a median point. f) Scale for getting enlargement ratio.

Before taking the lateral view with this instrument, the tips of two poles, right and left, indicating external auditory meatus, are adjusted at the same height and should be adjusted to be in accord with the center of X-ray by aid of optical indication in multiple leaf diaphragm. (Fig. 6 Shimazu Seisakusho Ltd., Tokyo). X-ray is projected horizontally.
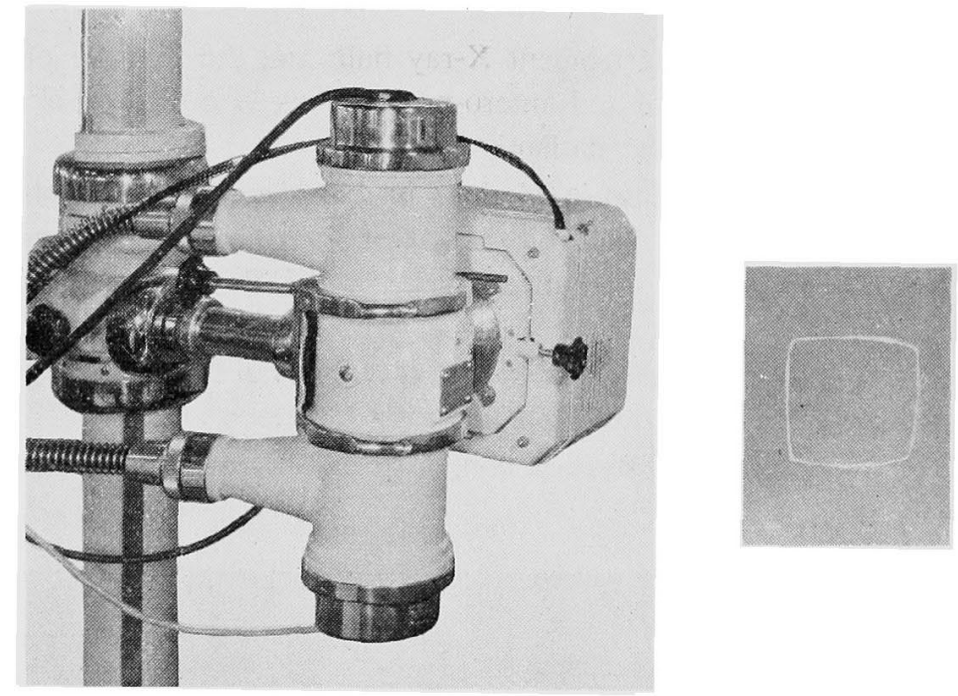

Fig. 6. Multiple leaf diaphragm with optical indication.

The center of X-ray guided by the optical indication in multiple leaf diaphragm shuld be adjusted to the pole indicating external auditory meatus attached to the frame of the side near the bulb, and then opening this cassetteframe, the center of X-ray is also adjusted to the pole on the frame of the opposite side. After this procedure, the whole instrument should be fixed to the floor with the weight block at the bottom rack of the table. This is done for the purpose of preventing its shift when the head of patient is placed into this instrument.

The patient's head is put on the lower fixing belts, and ear plugs with small metal mark are inserted into both of the external auditory meatuses. Then the position of the head should be decided correctly by each indicating poles and the head be fixed tightly with two upper fixing belts placed on his forehead and upper jaw, so that the poles indicating external auditory meatuses may touch both ear plugs with the same length of poles bilaterally and also the poles indicating 
inferior ridge of orbits on the transverse bars are put down in position, and the pole indicating the median point is placed on the midline.

The enlargement scale is placed into the mid-sagittal plane, because the both foramina of Monro are very closed to this plane.

The scale is again placed postoperatively into the other sagittal plane including the newly formed lesion which may be visualized with pantopaque.

After the film is loaded in the cassette-frame of the side far from the bulb, frame of the side near the bulb is opened and the indicating poles on the transverse bar are raised not to make any shadow on the film, the lateral view is taken (Figs. 7 and 8).

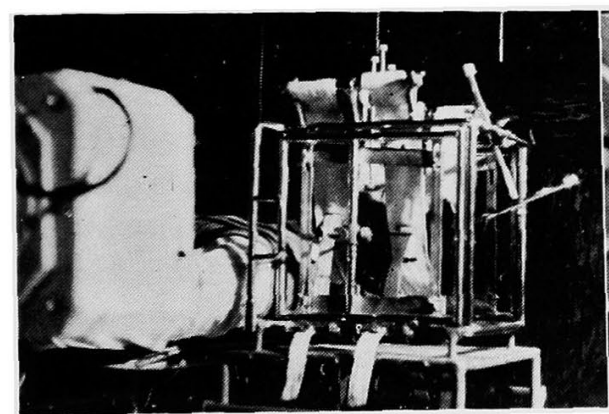

Fig. 7. Patient's head fixed in correct position.

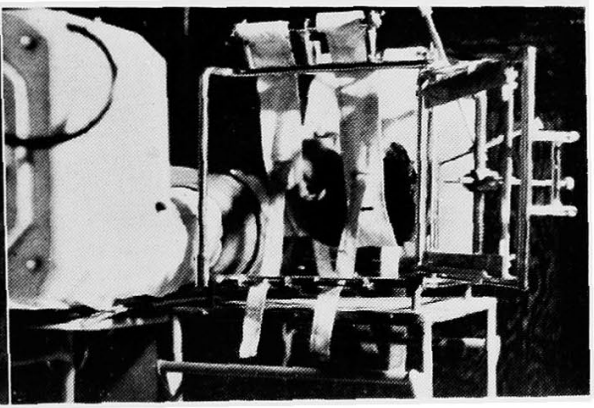

Fig. 8. Taking lateral view.

In taking an antero-posterior view, the head is not moved from the position where lateral view was taken, but the X-ray bulb is moved vertically right above the head so that the center of X-ray with aid of optic guide in multiple leaf diaphragm may be put down to the center of the pole indicating the midline. After placing the cassette with a film under the head on the table, transverse bar is removed before taking antero-posterior view.

The enlargement scale is put on the vertical plane including the intracerebral reference point preoperatively or destroyed point postoperatively.

This is one of the best method for the following advantages. The patient can stay on the stretchers; the head fixing belts have rolling parts and the stopper on both sides; and the patient's head can be moved freely before fixing, and fixed tightly during the procedure, so it is very easy to manipulate and settle the head in a correct position. The patient may also be burdenless and feels naturally lying on his back as he is accustomed to do.

\section{Discussion}

It is beyond question that the application of X-ray is the most indispensable factor for the stereotaxic surgery. And many of neurosurgeons have continued to use this procedure. Accordingly, the operating apparatus and instrument for 
correcting distortion in the cranial roentgenogram are one entity, as if they were two wheels of a bicycle. Talairach ${ }^{2 \tau}$ ) in Paris and Riecher ${ }^{24)}$ in Freiburg, who have contributed as much as Spiegel ${ }^{6) 7(13) 25) 26 \text { ) }}$ and Cooper ${ }^{5 / 9) 35) 36)}$ to this field, have thought it most important that roentgenogram should be taken at the correct position of the head and they appeared to have had much trouble in devising a means of avoiding distortion of the head.

For more than four years, attempts have been made on the cranial roentgenogram in our laboratory to make the measurements worthwhile. Model I has been thus modified to Model II, whose improved points are as follows:

(1) When the ventricles are completely filled with air, the pneumoencephalogram may be worthwhile to measure even with Model I, but in many cases, the ventricles can not be completely filled with air, so that the Model II has been devised to gather the air around the foramen of Monro, with the patient's head in brow-up position in order that the foramen of Monro (our intracerebral reference point) can be visualized clearly. Consequently, as will be explained in the following chapter, the foramen of Monro has been clearly visualized in 85.4 per cent of the cases by Model II. The degree of accuracy by this Model II surpasses Model I by 51.3 per cent.

(2) In the case of Model II, the instrument is so devised that the patient can stay on the stretcher and the lateral and antero-posterior views may be taken simply by moving the X-ray tube without moving the patient's head.

(3) With Model I, the ear plug to the crossmark on the bakelite board can hardly be adjusted exactly in the lateral views, and it is also a disadvantage that the head can not be moved up and down precisely because the upper and lower fixing belts can be rolled up only in one direction.

In the case of Model II, bilateral external auditory meatuses can be easily observed laterally and the indicating poles can be easily adjusted from side and

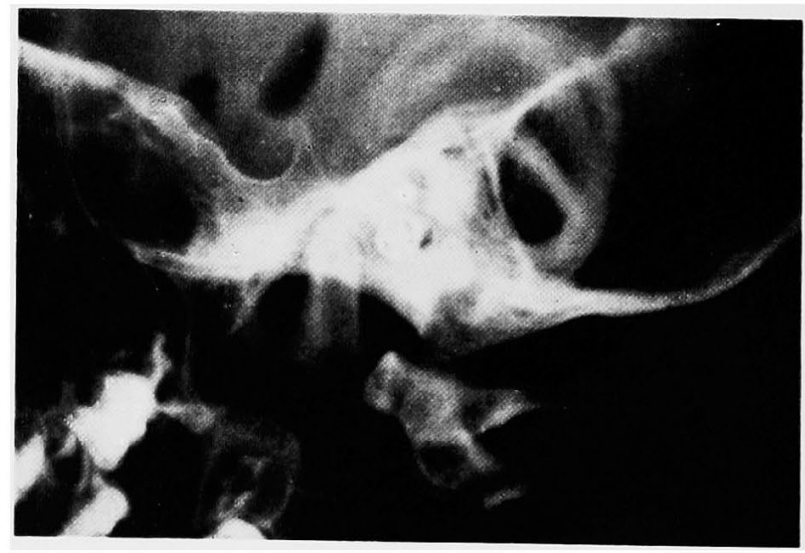

Fig. 9. Both right and left ear plugs are superimposed in lateral view (correct rentgenogram). 
the fixing belts have the rollers and stoppers on both sides. Thus the head can be settled in a proper position without rotation merely by rolling up the belts equally.

(4) As already mentioned, Model II has an enlargement scale and the enlargement rate in the measuring plane is recorded in the roentgenogram.

Therefore, Model II has greater advantages for taking the cranial roentgenogram worthy of measuring (Figs. 9, 10, 11 and 12).

If the position of globus pallidus is mainly determined by only anteroposterior pneumoencephalogram as illustrated in Fig. 13, there is a danger that positions of $\mathrm{a}, \mathrm{b}$ and $\mathrm{c}$, which are the base points, would be changed according to

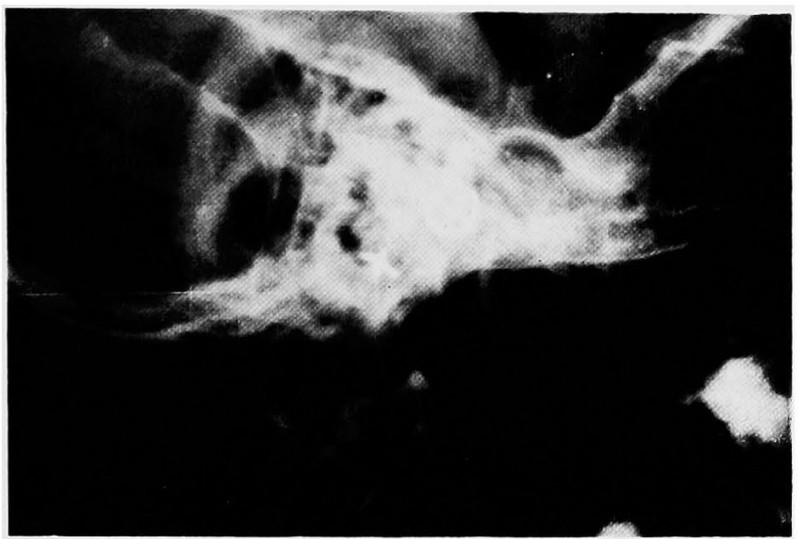

Fig. 10. Ear plugs are not overlapped (incorrect roentgenogram).

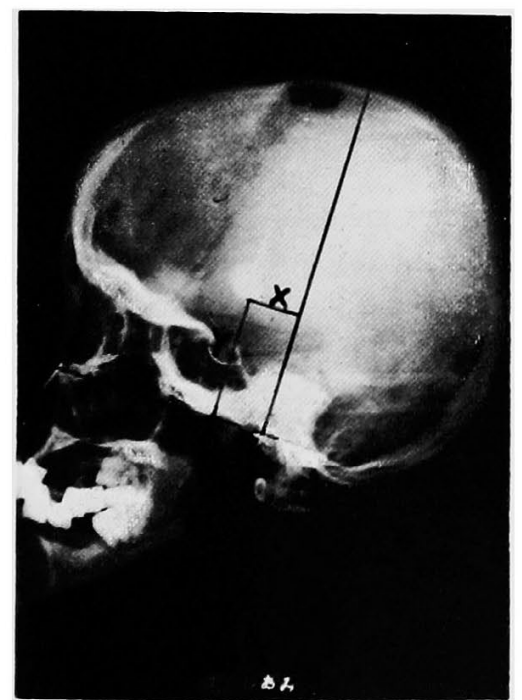

Fig. 11. Lateral view (Model II).

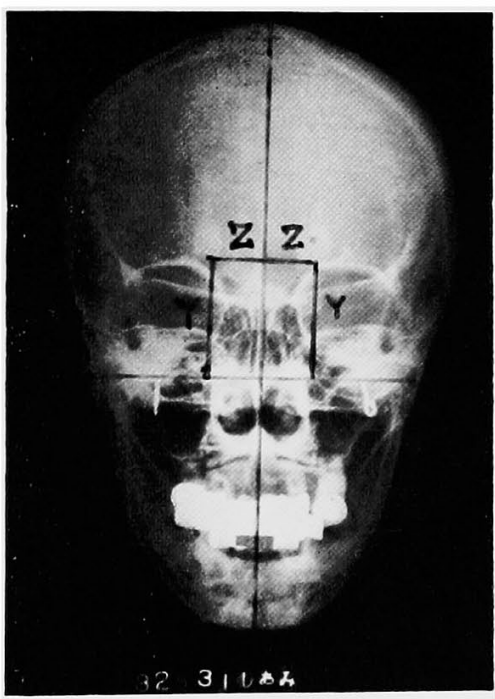

Fig. 12. A-P view (Model II). 


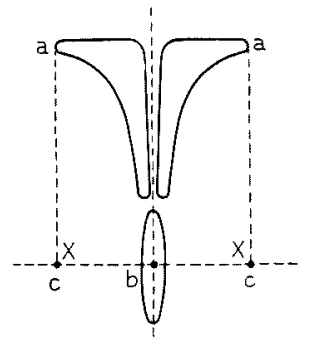

Fig. 13. a the most lateral point of the lateral ventricle $b$; the middle point of third ventricle

$c$; crossing point of two lines of the vertical line passing through a and the horizontal line passing through $b$

$\mathrm{x}$; the site of globus pallidus

the quantity of air within the ventricle and to the position of X-ray bulb and of the patient's head. It is not desirable due to excessive X-ray irradiation to have the needle replaced over and over again by the roentgenographic control. By our method two pictures i.e. the lateral and the antero-posterior views can attain enough the purpose of the preoperative roentgenogram. The horizontal and vertical distances from each base plane to the foramen of Monro (our intracerebral reference point) are measured in the lateral view. With these distances, the horizontal and vertical positions of the target are calculated respectively. But the midpoint of the both foramina of Monro are situated near the midsagittal plane so the position of the target lateral to the mid-sagittal plane is determined on the map (cf. chapter 3), with regard to the size and shape of the ventricles in antero-posterior view, considering that points $a, b$ and $c$, are variable according to the quantity of air within the ventricles.

\section{SUMMARY}

Model II was demonstrated to be more excellent than Model I so that pneumoencephalograms worthy of measuring are obtained. Advantages of this model are as follows:

(1) Foramen of Monro, the intracerebral reference point, is clearly and easily visualized.

(2) Exact lateral and antero-posterior views are taken without any shadow of the instrument, and the enlargement rate of the measuring plane in the roentgenogram is recorded and calculated.

(3) Structure of Model II is simple.

(4) The patient feels at ease as he lies on his back.

Our stereotaxic surgery has been performed more exactly by using this Model II, and satisfactory results have been obtained clinically.

\section{Part 2: X-ray studies}

In performing stereotaxic surgery, at present, many neurosurgeons usually adopt the intracerebral reference points pneumoencephalographically in the third 
ventricle such as the foramen of Monro, anterior commissnre and massa intermedia, etc., and the operation is controlled by these points. There were many difficulties in visualizing clearly these reference points pneumoencephalographically in all cases, it has been reported in the previous chapter that these difficulties are eliminated by the instrument (Model II) of the author's device.

In this chapter, investigations are made on the roentgenograms taken with Model II.

\section{The Percentage of Success in Pneumoencephalography}

As the judgement of success or failure in pneumoencephalography (PEG) depends sometimes upon clinician's own evaluation, so it is very difficult to prescribe a criterion for success, but the cases in which the shadow of the lateral ventricles were clearly identifiable, were judged as successful one.

The number of patient on whom PEG was performed is 468 , and the number of patients on whom PVG was performed is 124 in our clinic during the past 2 years. Most of these patients on whom PEG was performed are those with arachnoiditis $(45.0 \%)$ and epilepsy $(37.5 \%)$. Patients with extrapyramidal disorders are only 7.5 per cent and others are 10.0 per cent.

PEG is performed while the patient sits on his chair with the head being bent a little forward as a rule and the cerebrospinal fluid is replaced by air alternately by means of lumbar puncture. In this instance, intravenous narcosis is administered to relieve the headache and the other reactions caused by the loss of cerebrospinal fluid and by rapid changes in intracranial pressure.

Of 468 patients on whom PEG was performed for the two-year period, the percentage of success in the first PEG is 82.5 per cent, and the one in the second $\mathrm{PEG}$, which was tried again on those unsuccessful cases in the first PEG, is 52.2 per

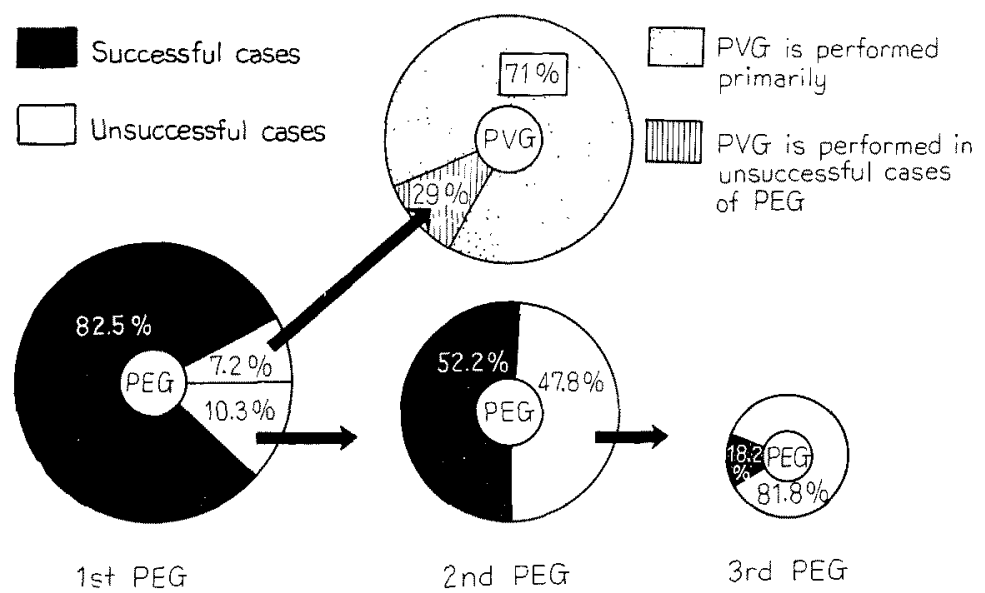

Fig. 1. Pneumoencephalography (PEG) \& Pneumoventriculography (PVG). 
cent and is 18.2 per cent in the third. Thus it may be said that PEG should be repeated even if the first trial proves to be unsuccessful (Fig. 1).

On examination of the relation between the quantity of air injected and the percentage of success in PEG, a steep rising curve is observed between the air quantity of $40 \mathrm{cc}$. and $60 \mathrm{cc}$. (Fig. 2). Namely, the percentage of success in PEG is 18.2 per cent with $40 \mathrm{cc}$. and 71.0 per cent with $60 \mathrm{cc}$. There is appreciable difference between them. The quantity of air more than $60 \mathrm{cc}$. is required to obtain successful PEG. As PEG is performed under slight intravenous narcosis and the reaction in PEG thus is alleviated, a large amount of air can be allowed to flow into the space in most of the patients. Its success in PEG depends upon an amount of air injected into subarachnoid space as well as to the positions of the head. The technical problems on PEG have been widely discussed in literature. ${ }^{3 \tau-46)}$

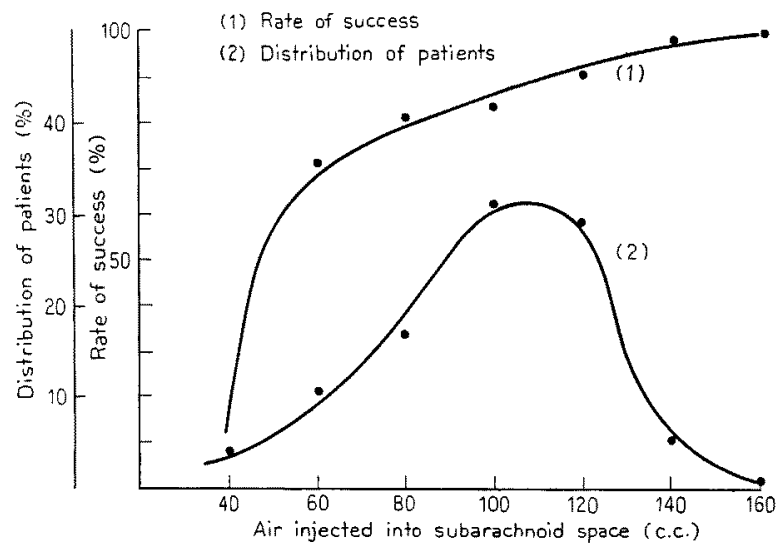

Fig. 2.

Lindgren ${ }^{40)}$ reports that it is possible to obtain success in 93.5 per cent (142 cases out of 1952) with the amount of air of only $25 \mathrm{cc}$., by controling the position of the patient's head and the speed of air flow. The method of PEG in which a small amount of air is injected with minimal withdrawal of the fluid, is recently advocated with many advantages, ${ }^{43-45}$ ) but the structure of the third ventricle is not clearly visualized in some of cases because of too small amount of air existing within the ventricle. On the other hand, Dandy ${ }^{41) 47)}$ and Twining ${ }^{48)}$ claim that a greater amount of air is needed for a higher percentage of success. It seems, however, that the proficiency in the technics and utmost care in PEG enabled Lindgren to attain such good results with such a small amount of air. On the basis of our statistics it may be said that at least more than $60 \mathrm{cc}$. of air yields satisfactory PEG. 
The Appearance of the Intracerebral Reference Point in the PNEUMOENCEPHALOGRAM

As was explained in the preceding chapter, the following conditions must be observed in order to measure the position of the intracerebral reference points in roentgenogram.

(1) A-P and lateral views should be taken at the constant and correct position of the head.

(2) The enlargement rate in pneumoencephalogram should be indicacted.

(3) The intracerebral reference points should be visualized clearly.

It has been already mentioned that Model II satisfies these conditions. In the present chapter the third item will be discussed in detail.

Observing 830 leaves of routine lateral pneumoencephalogram, in which air gathers mainly on one side of the ventricles, the foramen of Monro is clearly visible only in 18.5 per cent, comparatively clearly in 15.4 per cent, while Massa intermedia is clearly visible in $\mathbf{1 1 . 2}$ per cent and comparatively clearly in 5.6 per cent respectively. Consequently, the reference points are visible in only 37.5 per cent. Twining reported that the percentage of success in the routine lateral roentgenogram in which the third ventricle is clearly visible is only
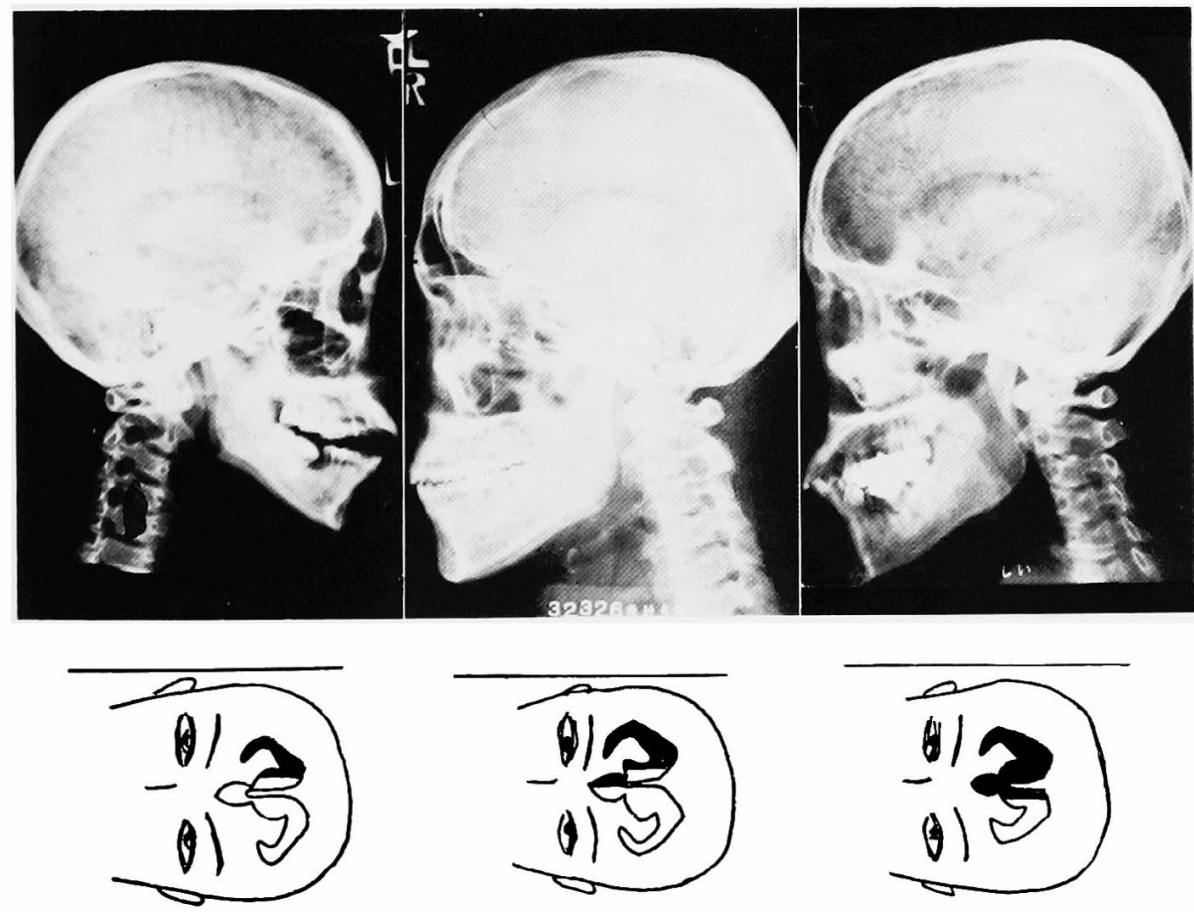

Fig. 3-5. 3 types of lateral view according to the quantity of air within the ventricles. 
about 10.0 per cent. Almost the same is true in the 415 cases of A-P views, in which the foramen of Monro is visualized clearly in 12.5 per cent, and comparatively clearly in 7.5 per cent (Figs. 3, 4 and 5).

The reasons why the foramen of Monro and massa intermedia are visible in a low percentage in the routine PEG are thought to be as follows:

(1) The shadow of air in subarachnoid space of the cortex are superimposed.

(2) The third ventricle is anatomically narrow in width.

(3) In some cases, crista frontalis et galli is quite thick and large, whose shadow is superimposed in A-P views.

(4) The injected air gathers in the longitudinal fissure, etc. (Fig. 6).

Even when the pneumoencephalography is successful, the reference points are visible at a low percentage, thus presenting great obstacles in taking a roentgenogram to be worth measuring for stereotaxic surgery. Almost all cases, however, reveal air within the third ventricle in A-P view, and therefore, a better roentgenogram with a clearly visible reference point may be obtained, if the lateral view is projected in brow-up position. This can be realized in Model II, as stated in the preceeding chapter with which the foramen of Monro has clearly been visualized in a high percentage $(97.0 \%)$ in the lateral view of successful cases. Massa intermedia has, however, been visualized only at the rate of 16.0 per cent on account of air gathering in the frontal part of the third and lateral ventricles (Fig. 7).
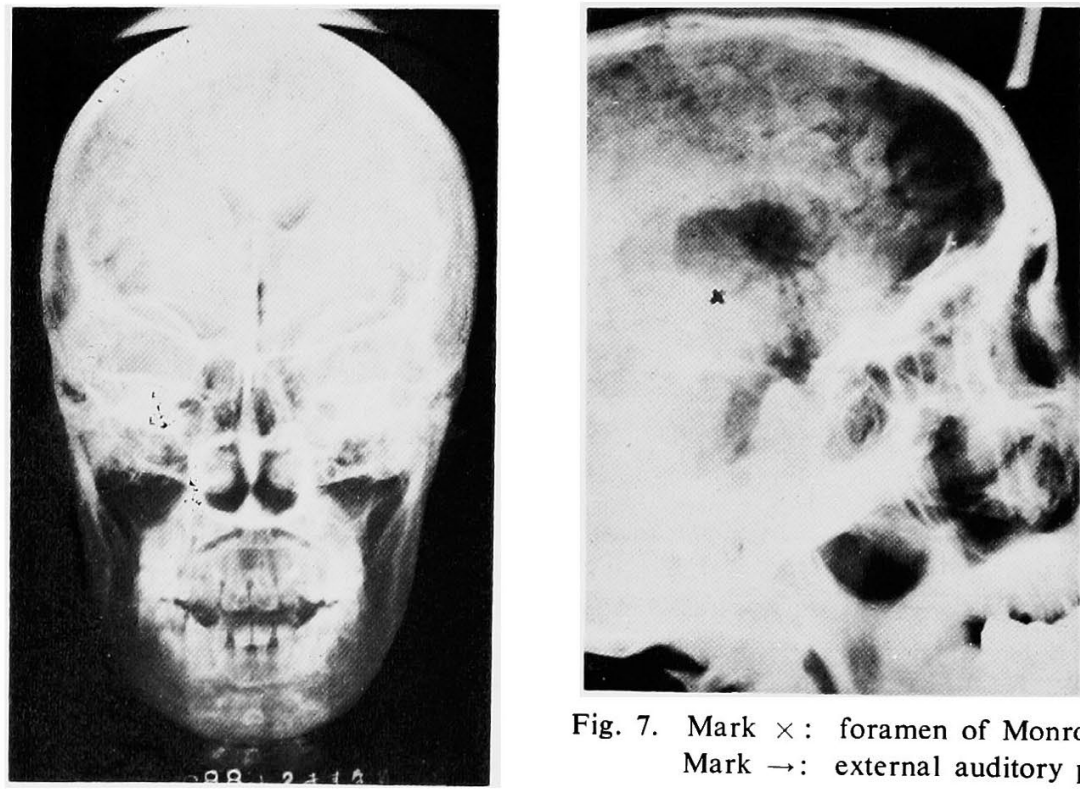

Fig. 7. Mark $\times$ : foramen of Monro Mark $\rightarrow$ : external auditory poles.

Fig. 6. Marked shadow of crista frontalis et galli and air in subarachnoid space. 
By this method there are also a few cases whose foramen of Monro cannot be identified clearly because of a large volume of air in the subarachnoid space of the cortex. In such cases, for the purpose of visualizing the foramen of Monro more distinctly, the picture is taken after having the patient lie on his back for about 24-36 hours. In this way air in the subarachnoid space gathers to the frontal part, thus giving homogeneous shadow in the picture (Fig. 8).

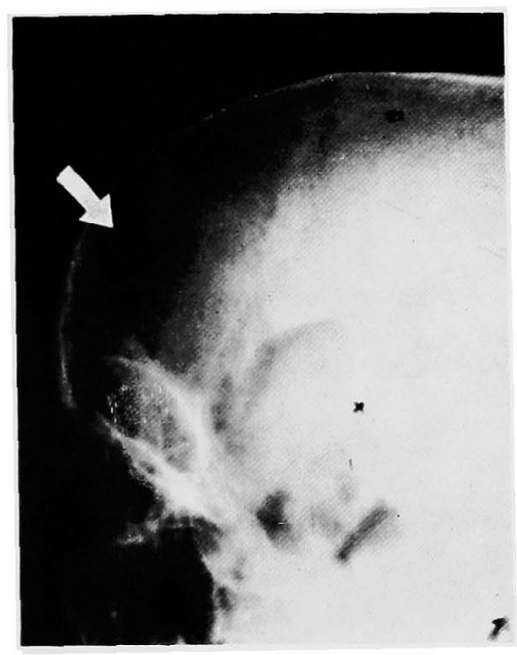

Fig. 8. Mark $\rightarrow$ : homogeneous shadow of air gathered in the frontal subarachnoid space.

Mark $x$ : foramen of Monro.

Mark $\rightarrow$ : external auditory poles.

This method has already been used, following Twining's, ${ }^{48)}$ Lysholm's, ${ }^{49)}$ and Balado's ${ }^{50}$ ) experiences, as the best method of visualization of the foramen of Monro. And this is also observed and experienced in our cases independently.

The percentage of success in PEG by our method proves to be 88.0 per cent, and accordingly, with the Model II, the foramen of Monro is identified clearly in 85.4 per cent of all PEG cases.

\section{The Range of Error in Our Stereotaxic Surgery}

The accuracy of the operation is considered to be the most important problem in the stereotaxic surgery to produce a deep-seated cerebral lesion without visual control. The position and shape of the lesion are checked postoperatively by roentgenographic studies with injection of procaine oil and wax mixed with pantopaque.

The shape of injected oil and wax mixture is classified into five types as illustrated in Table 1. The main destructive lesion is situated on the position $2-3 \mathrm{~mm}$. backward from the tip of the needle, as most of the injected oil and wax mixture flows backwards along the needle (Fig. 9).

The relationship between the tip of needle and the deepest point of the injected oil and wax mixture is observed in those with comparatively regular 
TABLE 1

\begin{tabular}{|c|c|c|c|c|}
\hline & \multicolumn{2}{|c|}{$\begin{array}{c}\text { Shapes of injected } \\
\text { oil - wax }\end{array}$} & Cases & $\begin{array}{c}\text { Per } \\
\text { cent } \\
(\%)\end{array}$ \\
\hline 1 & Globular & 1 & 17 & 43.6 \\
\hline 3 & Oval & 1 & 12 & 30.8 \\
\hline 4 & $\begin{array}{c}\text { Long and } \\
\text { Slender } \\
\text { blocks }\end{array}$ & 5 & 5 & 12.8 \\
\hline 5 & $\begin{array}{c}\text { Flowed. } \\
\text { horizontally }\end{array}$ & & 3 & 7.7 \\
\hline & \multicolumn{2}{|c|}{\begin{tabular}{c} 
Total \\
\hline
\end{tabular}} & 39 & 100.0 \\
\hline
\end{tabular}

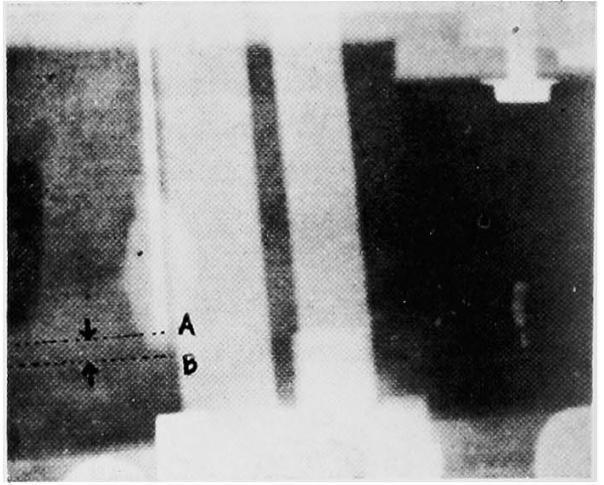

Fig. 9. A: tip of needle.

B : deepest point of injected oil and wax with pantopaque.

shape (1) and (2) groups in Table 1, and the distance between them is $2.5 \mathrm{~mm}$. (Fig. 9). Then the errors in stereotaxic surgery are counted, comparing the position of the tip of the needle on postoperative roentgenograms with the position at which we aimed (Figs. 10 and 11 and Table 2).

According to $\mathrm{N}(0.59,0.39)$ formula, as the error, i.e. the distance from the target to the tip of the needle is considered to range in the Gauss's distribution.

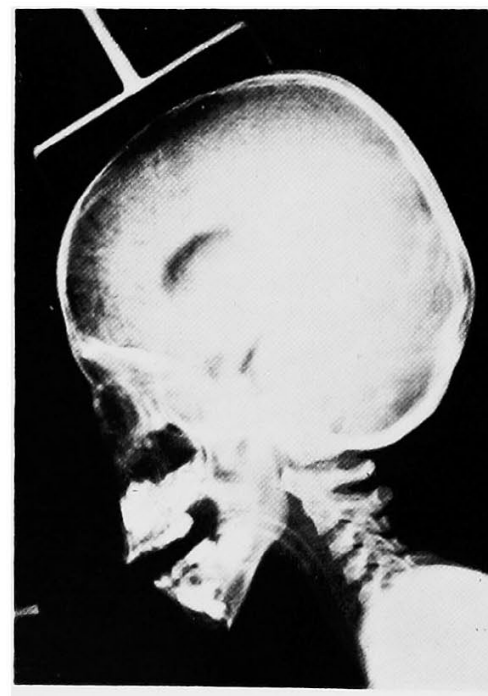

Fig. 10 .

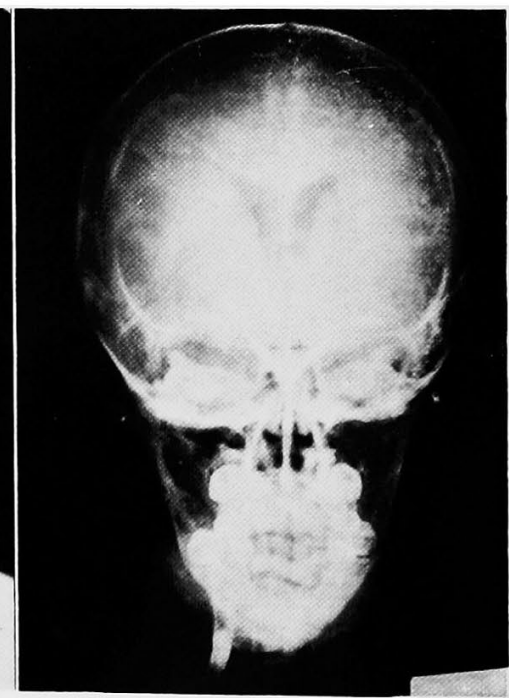

Fig. 11 . 
TABLE 2.

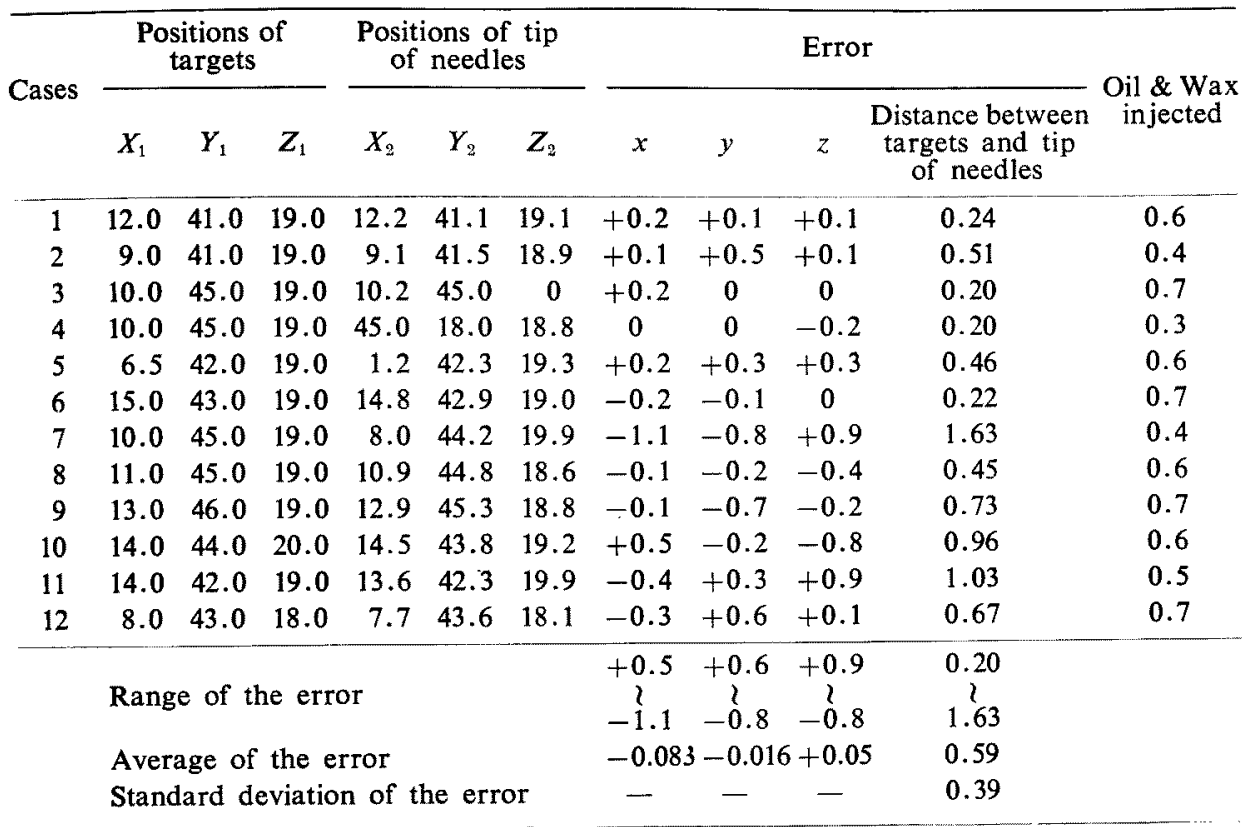

$$
\begin{aligned}
& P\left(\frac{x-0.59}{0.39} \leqq Z<\infty\right)=0.05 \\
& \phi(\infty)-\phi\left(\frac{x-0.59}{0.39}\right)=0.05 \\
& \phi\left(\frac{x-0.59}{0.39}\right)=0.45 \\
& \frac{x-0.59}{0.39}=\phi^{r}(0.45) \\
& x=1.23155
\end{aligned}
$$

It may safely be said that 95 per cent of our operations has been performed in the range of error within $1.24 \mathrm{~mm}$. This result seems to be very satisfactory in aiming at globus pallidus or ventrolateral nucleus of the thalamus, but it must be emphasized that satisfactory results can be expected only if one scrupulously adheres to the details of the technic, particularly the exact application of the apparatus (stereoencephalotome) at surgery.

\section{SUMMARY}

The visualization of our intracranial reference point in PEG, which is a basic problem of the stereotaxic surgery, and the range of error of the surgery are discussed in the present chapter. 
(1) For the success in PEG, it is necessary to inject more than $60 \mathrm{cc}$. of air into intraspinal space.

(2) Model II, an instrument for correcting distortion in the cranial roentgenogram, is much superior to Model $I$ in visualizing the foramen of Monro, the intracerebral reference point of author's selection.

(3) From the range of error in our surgery, it has been clarified that the surgery is performed accurately.

\section{Part 3: Spatial relationship between the foramen of Monro and subcortical nuclei}

Concerning the spatial relationship between each subcortical nuclei, Spiegel and Wycis established a coordinate system with respect to the structures within the brain, visible in the plain roentgenograms (pineal) or distinguishable in pneumoencephalogram (i.e., suprapineal recess, posterior commissure and anterior commissure), and investigated them with 30 autopsies in 1947. ${ }^{25}$ ) Housepian and Carpenter, also, reported the spatial relationship between the globus pallidus and the anterior commissure with 11 autopsies in $1957 . .^{51}$ )

These data have been, however, obtained by investigations on Europeans. and therefore, they may not exactly be applicable to the Japanese as there would be some differences among various races. Co-ordinates for the human brain have been determined by the authors with respect to three intersecting planes: 1) the horizontal base plane determined by the bilateral inferior ridges of orbits and external auditory meatuses, 2) the vertical base plane passing through the auditory meatuses, and perpendicular to the horizontal plane, and 3 ) mid-sagittal plane.

In 1954, Narabayashi reported that the position of pallidal globus is situated $3-5 \mathrm{~mm}$ anterior, $5 \mathrm{~mm}$ inferior and $20 \mathrm{~mm}$ lateral to the center of massa intermedia in 6 autopsies. The position of pallidal globus has also been investigated by the authors with respect to the foramen of Monro, performing pneumoencephalography and aiming at the pallidal globus with our stereotaxic apparatus on 10 autopsy cases, and then, observed that the position of $5 \mathrm{~mm}$ posterior, $10 \mathrm{~mm}$ inferior and $19 \mathrm{~mm}$ lateral to the midpoint of the both foramina of Monro is the best point aiming at the pallidal globus.

These data have been utilized in our surgery, and brought good results. However, these are only for the pallidal globus, so that spatial relationship between the subcortical nuclei and the intracerebral reference points such as the foramen of Monro, anterior commissure and massa intermedia, etc. must be measured exactly in considerable number of the Japanese autopsy cases.

In the present paper, the shape and the spatial disposition of the pallidal globus, lateral group of the thalamic nuclei, red nucleus, substantia nigra, corpus 
Luysi, anterior commissure with respect to the foramen of Monro and inclinations of the internal capsule to mid-sagittal plane were observed in 19 Japanese autopsies.

\section{Materials}

The materials used in this study consisted of 19 brains of the Japanese obtained at autopsy. The age of the patients ranged from 20 to 71 years and ten of them were male and nine female. They all died of nonneurologic diseases (Table 1).

TABLE 1. Materials

\begin{tabular}{|c|c|c|c|}
\hline Autopsy number & ages & $\operatorname{sex}$ & Cause of death \\
\hline 1 & 61 & $\hat{s}$ & gastric cancer \\
\hline 2 & 64 & 오 & esophageal cancer \\
\hline 3 & 29 & $\hat{o}$ & leukemia \\
\hline 4 & 62 & 우 & gastric cancer \\
\hline 5 & 24 & $\hat{\delta}$ & aplastic anemia \\
\hline 6 & 33 & 古 & uraemia \\
\hline 7 & 22 & 우 & leukemia \\
\hline 8 & 58 & 우 & hepatic cancer \\
\hline 9 & 71 & 占 & bronchial carcinoma \\
\hline 10 & 22 & 1 & leukemia \\
\hline 11 & 44 & 오 & hyperthyroidism \\
\hline 12 & 47 & 今 & hepatic cancer \\
\hline 13 & 20 & 우 & myasthenia gravis \\
\hline 14 & 21 & 우 & Hodgkin's disease \\
\hline 15 & 46 & 우 & pancreatic cancer \\
\hline 16 & 52 & 우 & pulmonary cancer \\
\hline 17 & 64 & 令 & esophageal cancer \\
\hline 18 & 62 & 古 & gastric cancer \\
\hline 19 & 63 & $\hat{\delta}$ & hepatic cancer \\
\hline
\end{tabular}

Since the brain is very soft tissue containing much water, it changes its configuration, even only by its own weight, as soon as it is taken out of cranial cavity, and moreover, it shrinks in the volume on fixation.

Spiegel et al. used the brain fixed in the cranial cavity and Housepian and Carpenter used it adjusted at the angle formed by the plane of the basal surfaces of the temporal and occipital lobes and a line projected along the orbital surface of the frontal lobes toward the frontal poles measured approximately 140 degrees.

It is very difficult to preserve the configuration and the volume of the brain under the conditions in vivo. The brain was perfused with $1000 \mathrm{cc}$. of a 10 per cent formalin solution containing 0.9 per cent $\mathrm{NaCl}$ and 5.6 per cent gum acacia from juglar veins in order to avoid the deformation and shrinkage of the brain.-This method is considered to be the best, but it requires a long period 


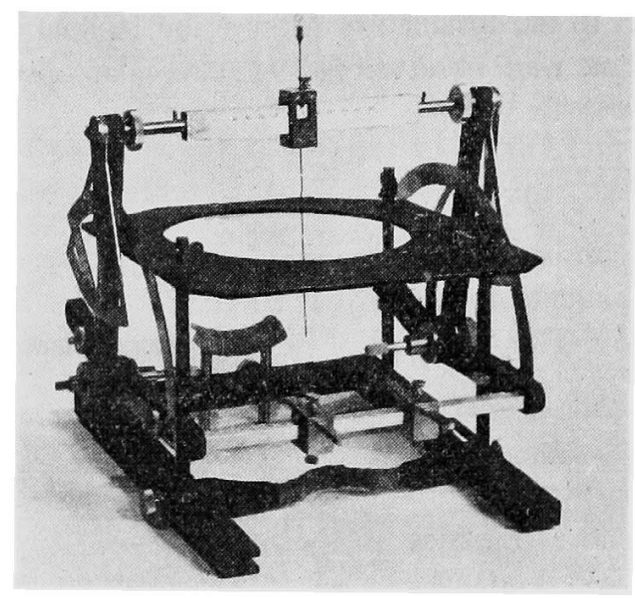

Fig. 1. The stereotaxic apparatus (stereoencephalotome). Model I.

of time before the brain is removed from the cavity, so that it is a very inconvenient method. Therefore, instead of it, the author managed the brain in order to keep the deformation and shrinkage at minimum with the following procedures.

The sterotaxic apparatus Model I (Fig. 1) is applied to the head of the autopsy case, and four needles are inserted into the brain $20 \mathrm{~mm}$ and $40 \mathrm{~mm}$ lateral on either side of the mid-sagittal plane through 4 burr holes, and in zero position of the apparatus in the vertical plane passing through the auditory meatuses and perpendicular to the horizontal plane. Carbon black oil and wax mixture is poured through the needle while pulling the needle slowly back, so that four poles of black oil and wax mixture may be made within the brain, and these are so kept in the brain as to indicate the deformation and shrinkage of the brain in following procedures (Fig. 10).

After removing the apparatus, the brain is removed from the cranial cavity in the usual way, and immediately put into the water to correct the deformed configuration, then it is suspended on the basilar artery in 20 per cent formalin solution containing 0.9 per cent $\mathrm{NaCl}$ for 10-12 days.

Precise measurements are made in five cases to estimate the grade of deformation or shrinkage of hemispheres.

(1) In order to decide the size of cerebral hemispheres within the cranial cavity, the height of oil and wax mixture poles are measured as dorsoventral length, and anteroposterior and lateral length of hemispheres are measured directly before removing the brain out from the cranial cavity. Measuring points are marked with black spots and hereafter, the measurements are taken between the same points.

(2) Immediately after removing from the cavity, and brain is placed into water to restore the intracranial configuration, and above-mentioned distances are measured respectively. 
TABLE 2.

\begin{tabular}{|c|c|c|c|c|c|c|c|c|}
\hline \multirow{2}{*}{ No. } & & \multicolumn{2}{|c|}{ A-P Length } & \multicolumn{4}{|c|}{ Dorso-Ventral length } & \multirow{2}{*}{ Lateral distance } \\
\hline & & $r$. & $l$. & $r \cdot(4)$ & $r \cdot(2)$ & l. (2) & l. (4) & \\
\hline \multirow{4}{*}{5 (1) } & (1) & 16.2 & 16.2 & 9.7 & 10.0 & 9.7 & 9.1 & 13.1 \\
\hline & (2) & 11.2 & 16.2 & 9.6 & 10.1 & 9.6 & 9.2 & 13.1 \\
\hline & (3) & 16.3 & 16.2 & 9.5 & 9.8 & 9.6 & 9.2 & 13.2 \\
\hline & $\mathbf{D}$ & +0.61 & 0 & -2.06 & -2.0 & -1.02 & +1.1 & +0.75 \\
\hline \multirow{4}{*}{$6(F)$} & (1) & 16.8 & 16.9 & 9.2 & 10.5 & 10.1 & 9.3 & 14.3 \\
\hline & (2) & 16.9 & 16.9 & 9.3 & 10.3 & 10.0 & 9.2 & 14.3 \\
\hline & (3) & 16.8 & 17.1 & 9.0 & 10.0 & 9.9 & 9.4 & 14.2 \\
\hline & $\mathrm{D}$ & 0 & +1.02 & -2.17 & -4.75 & -1.99 & +1.08 & -0.7 \\
\hline \multirow{4}{*}{$7(G)$} & (1) & 15.2 & 15.2 & 8.8 & 9.9 & 10.1 & 8.6 & 12.8 \\
\hline & (2) & 15.0 & 15.2 & 8.6 & 9.7 & 10.1 & 8.4 & 12.7 \\
\hline & (3) & 14.9 & 15.0 & 8.6 & 9.7 & 9.8 & 8.4 & 12.7 \\
\hline & D & -1.95 & -1.33 & -2.28 & -2.02 & -2.97 & -2.33 & -0.78 \\
\hline \multirow{4}{*}{$9(1)$} & (1) & 15.3 & 14.9 & 8.6 & 9.7 & 9.7 & 9.1 & 13.5 \\
\hline & $(2)$ & 15.3 & 15.1 & 8.4 & 9.4 & 9.7 & 9.0 & 13.4 \\
\hline & (3) & 15.0 & 15.3 & 8.5 & 9.5 & 9.6 & 9.0 & 13.5 \\
\hline & D & 0 & +2.68 & -1.16 & -2.1 & -1.04 & -1.11 & 0 \\
\hline \multirow{4}{*}{$10_{(J)}$} & (1) & 16.4 & 16.5 & 9.4 & 9.7 & 9.7 & 9.7 & 13.2 \\
\hline & (2) & 16.3 & 16.4 & 9.2 & 9.6 & 9.6 & 9.4 & 13.2 \\
\hline & (3) & 16.5 & 16.6 & 9.2 & 9.7 & 9.6 & 9.4 & 13.1 \\
\hline & $\mathrm{D}$ & +0.61 & +0.61 & -2.13 & 0 & -1.03 & -2.06 & -0.76 \\
\hline
\end{tabular}

Note: Cerebral hemispheres are measured.
(1) Within the cranial cavity.
(2) Immediately after the removal
(3) Fixed in 20\% formalin for 10-12 days.
D. Deformation rate $\frac{(3)-(1)}{(1)} \times 100$.

(3) Next, the brain, suspended on the basilar artery, is fixed in 20 per cent formalin solution for 10-12 days according to the routine procedures, and measurements are taken by the same method already mentioned.

As illustrated in Table 2, there is no remarkable deformity or shrinkage of the brain in this method. It is possible to measure the site of the subcortical nuclei by this method. There is, however, a tendency of shrinking in dorsoventral length and of elongation in antero-posterior length of about 1-2 mm respectively. No change is observed in the lateral length. 


\section{Brain-slicing Apparatus (Macrotome) and Sections}

A brain-slicing apparatus (macrotome) was devised so as to make frontal serial sections of the brain in parallel to the vertical base plane (Fig. 2).

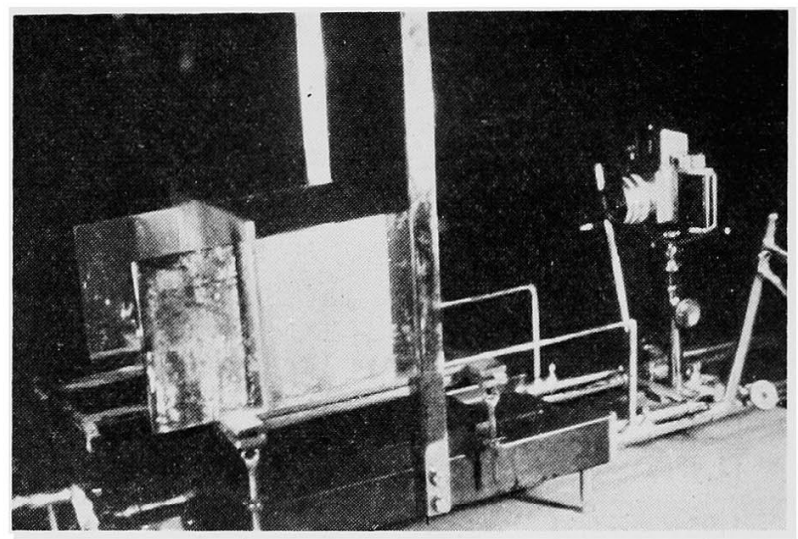

Fig. 2. The brain-slicing apparatus (macrotome).

The macrotome: Four carbon black oil and wax poles, situated at the point of $20 \mathrm{~mm}$. and $40 \mathrm{~mm}$. lateral and in parallel to the mid-sagittal plane in the vertical base plane, have already been set in the brain.

At first, these four oil and wax poles are replaced with four needles $(3 \mathrm{~mm}$. in caliber, $385 \mathrm{~mm}$. in length) respectively with needle guide (Fig. 3). And the brain with four needles is brought into the embedding-box, and the vertical plane, indicated by four needles, is placed in the position corresponding to the anterior plane of knife-guide poles. In this position, two needles are inserted laterally through two pairs of holes in both side-walls of the embedding-box, using the needle guide. And now, the brain in the embedding-box is supported at the temporal and occipital lobe by these two needles (Fig. 4).

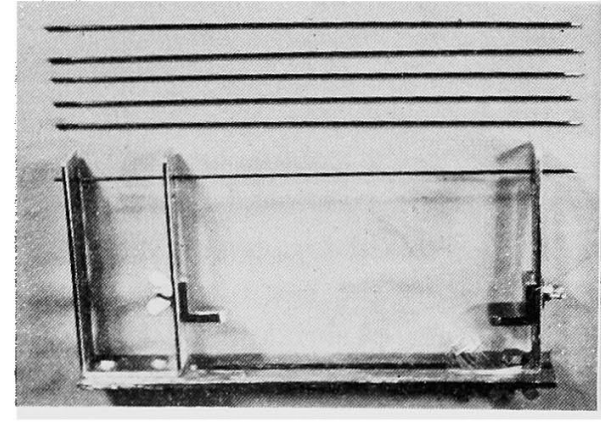

Fig. 3. Needles and the needle guide.

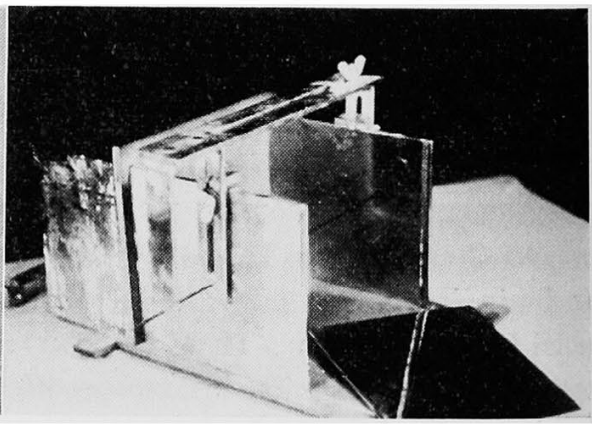

Fig. 4. The embedding-box with the needle guide. 
All edges of embedding-box are pasted over with an adhesive plaster and then, hot water containing 10 per cent agar-agar is poured into the box to embed the brain.

After the agar-agar has coagulated,- - taking usually 24 hours-, two needles supporting the brain are removed.

The table, on which the embedding-box lies, is fixed on the sliding board with bolts and screws on its corners and is adjustable in any direction. Now, it is again tested and adjusted whether or not the vertical plane indicated by four needles is in accord with the frontal plane of knife guide poles.

Removing the front board of the box, the sliding board is moved back by turning the handle so that the frontal plane of the embedding-box coincides with the frontal plane of knife guide poles. When the handle is turned in reverse direction, the sliding board is moved exactly forward $1 \mathrm{~mm}$ at each revolution.

Both of the side-walls of the embedding-box stand on the grooves in the bottom and the back-wall. When the stoppers on the side-wall are fixed, the side-wall is always kept $3 \mathrm{~mm}$ back of the frontal plane of knife guide, even if the sliding board are pushed forwards by the handle.

Accordingly, the parts of the box which move forwards with sliding board are on the bottom and the back-wall, and consequently the contents in the box (agar-agar and brain) are pushed forward by the bottom and the back-wall, and deflexion is prevented by the side-walls.

The sharp knife $(0.18 \mathrm{~mm}$ in thick, $4 \mathrm{~cm}$ in width and $60 \mathrm{~cm}$ in length) is slid along the frontal plane of the knife-guide poles and cuts the brain into sections of $2-5 \mathrm{~mm}$ in thickness. The cutting edge of knife is very thin, sharp and long enough to cut down the brain at one sliding.

Each section is covered with transparent plastic board with the lattices of $1 \mathrm{~cm}$ square, and the picture of the section is taken by the recording camera attached to the apparatus (Figs. 5-12).

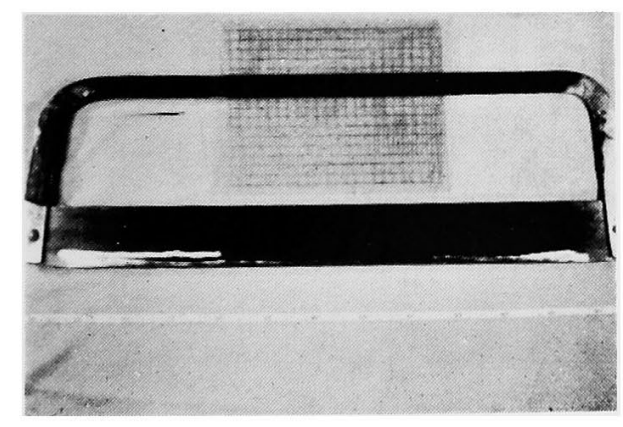

Fig. 5. The knife and the transparent plastic board which is marked $1 \mathrm{~cm}$ lattice. 


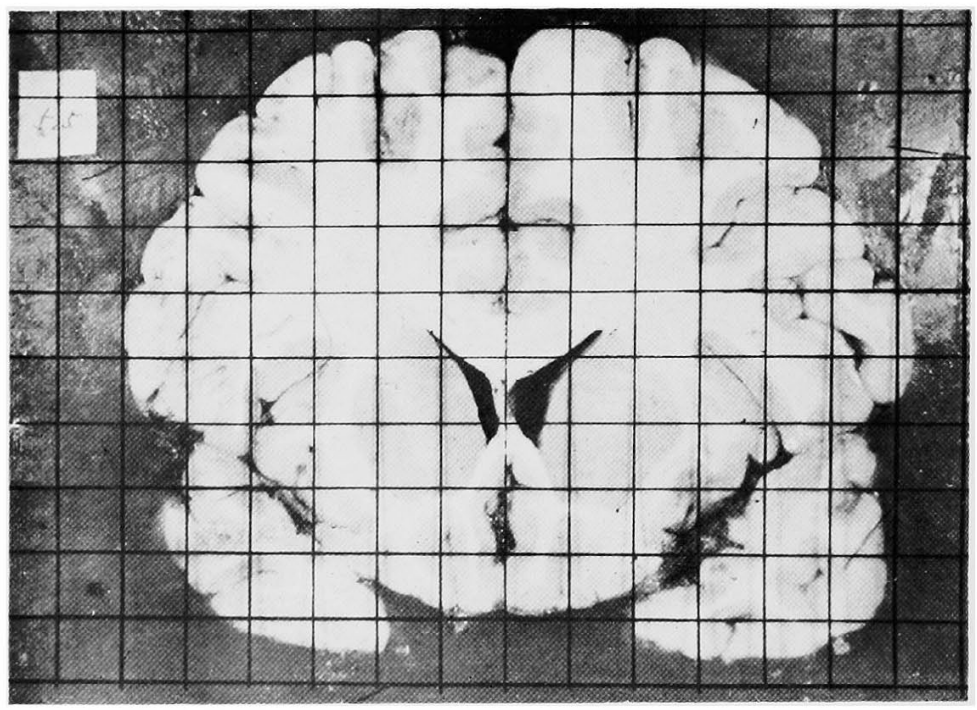

Fig. 6 .

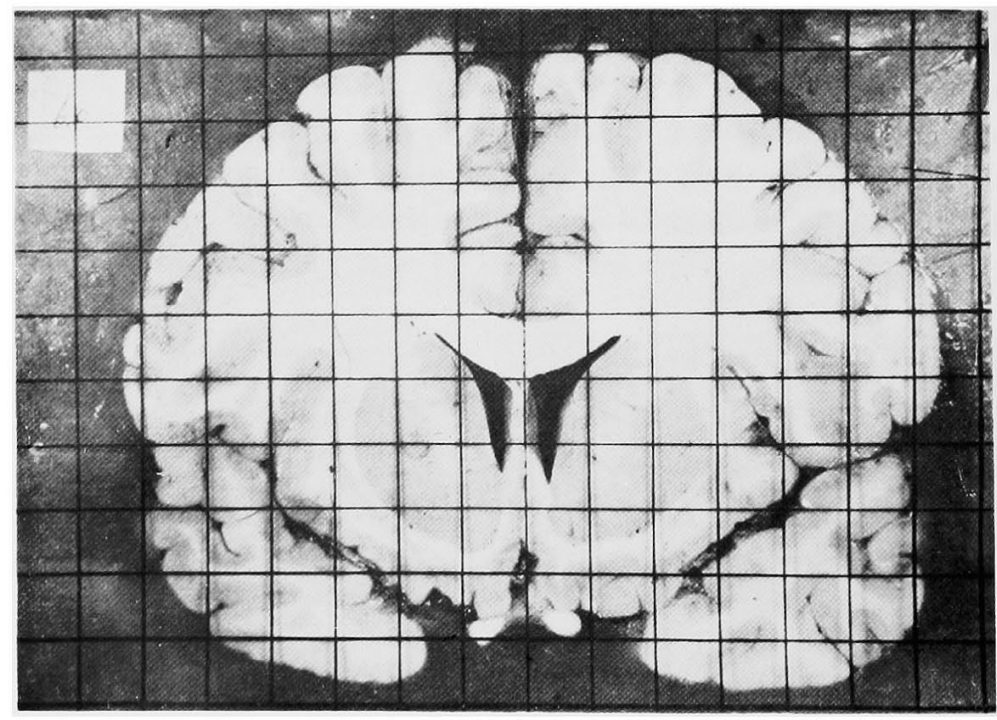

Fig. 7. 


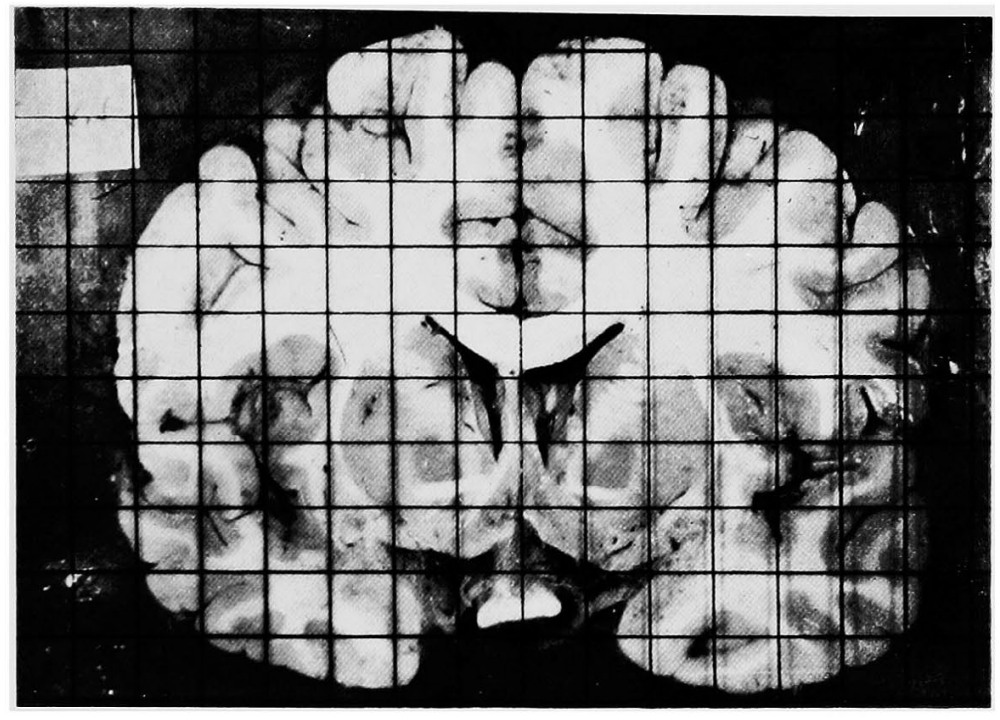

Fig. 8 .

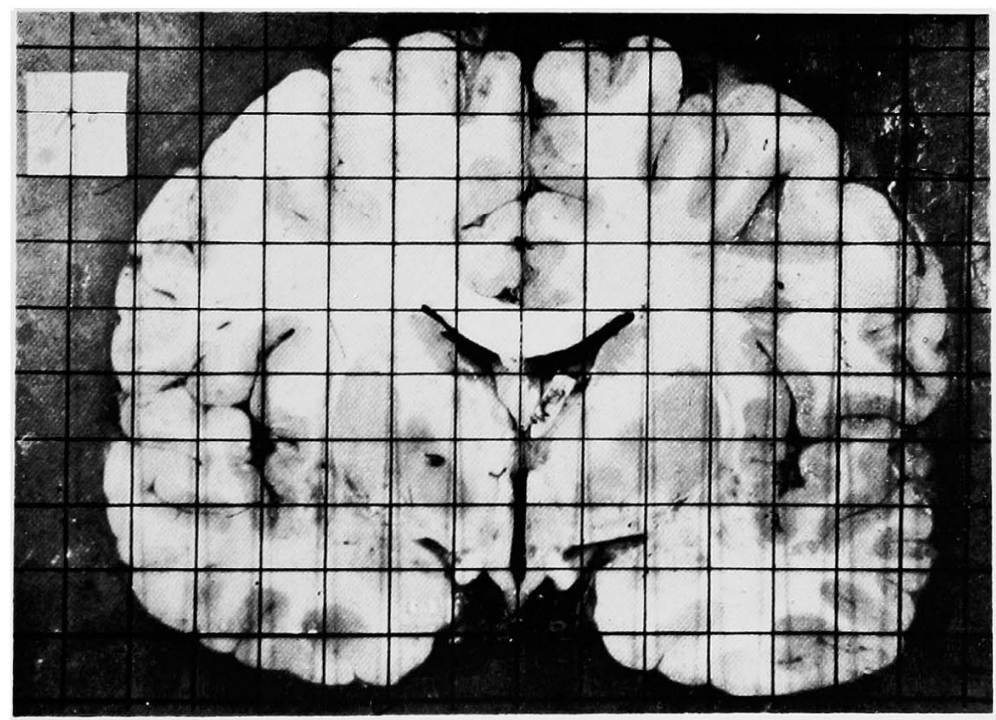

Fig. 9. 


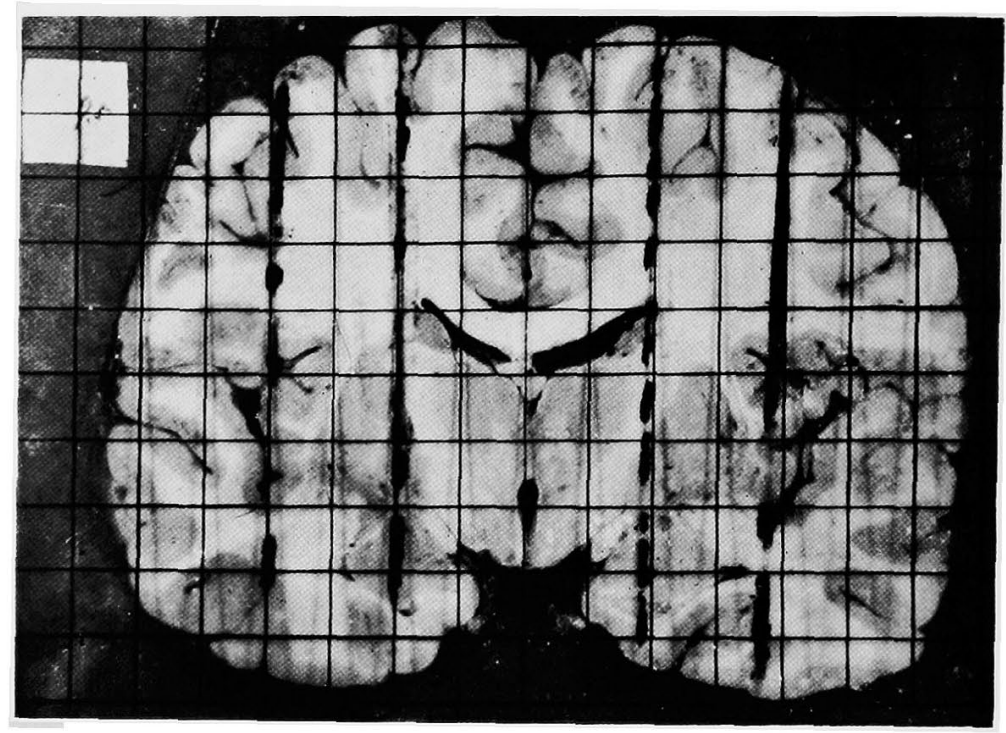

Fig. 10 .

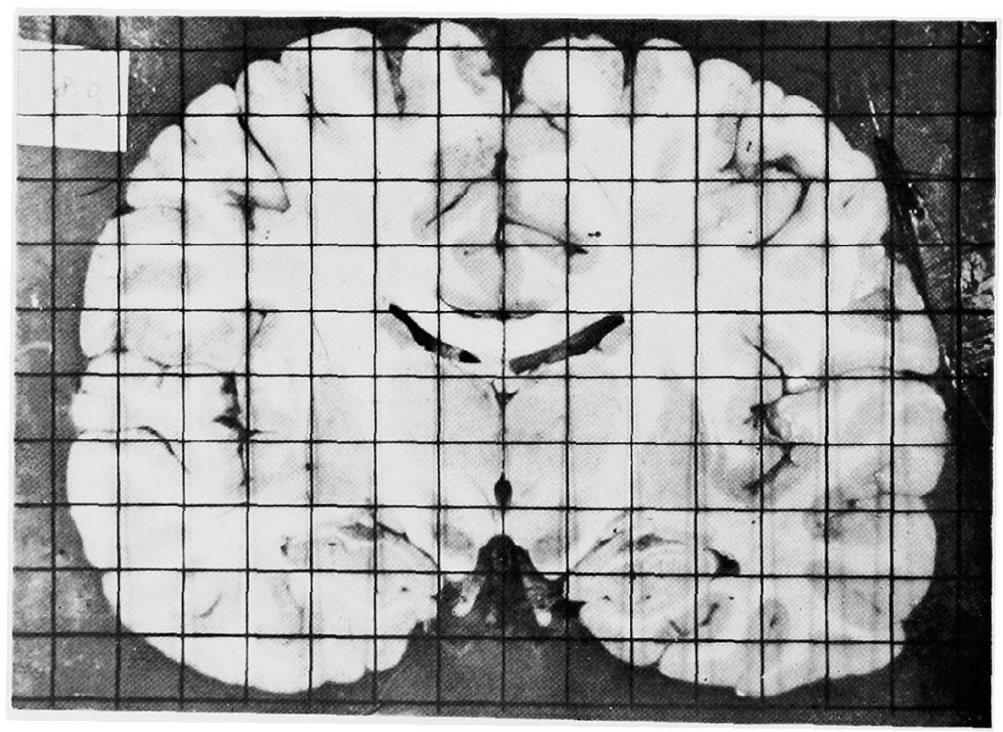

Fig. 11. 


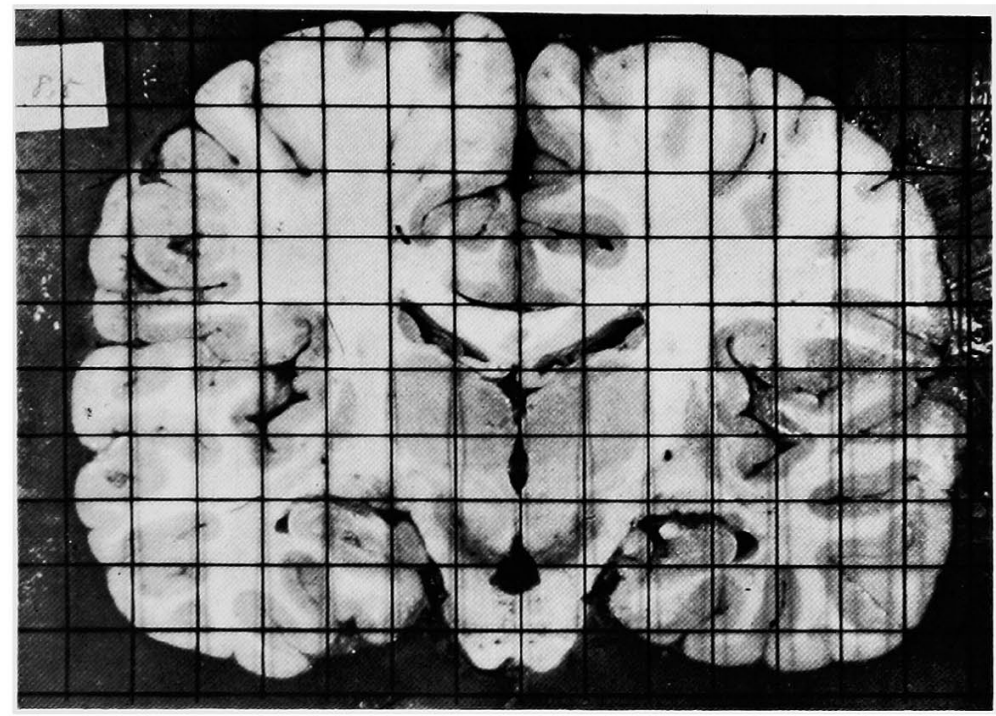

Fig. 12.

\section{Spatial Relationship Between the Foramen of Monro and Subcortical Nuclei}

1) The site of pallidal globus. Spiegel and Wycis established co-ordinates with respect to the center of the pineal body or the posterior commissure, and investigated the site of the pallidal globus in their co-ordinates. For the practical and clinical convenience, a graphic method of representation was used for determining the general size, shape and disposition of the pallidal globus to facilitate establishment of the stereotaxic co-ordinate system.

A provisional co-ordinate system was established with three intersecting spatial axes, 1) $\mathrm{X}$ axis is parallel to the horizontal plane in the mid-sagittal plane and passes through the midpoint of the both foramina of Monro, 2) $\mathrm{Y}$ axis is perpendicular to the horizontal plane, passing through the midpoint of the both foramina of Monro, 3) $\mathrm{Z}$ axis is perpendicular to the mid-sagittal plane through the foramen of Monro.

From this co-ordinate system the foramen of Monro (our intracerebral reference point) is selected as the zero point and somewhat similar to that of Housepian and Carpenter who took the center of the anterior commissure as the zero point.

The shape of the pallidal globus is a tetrahedron which has its bottom facing toward the temporal, and the minimal composite zones in superimposed projections of the pallidum are $11.5 \mathrm{~mm}$. in height $(1.5 \mathrm{~mm}$ above and $10.0 \mathrm{~mm}$ below to the foramen of Monro), $14.0 \mathrm{~mm}$ in length $(3.0 \mathrm{~mm}$ anterior and $11.0 \mathrm{~mm}$ 


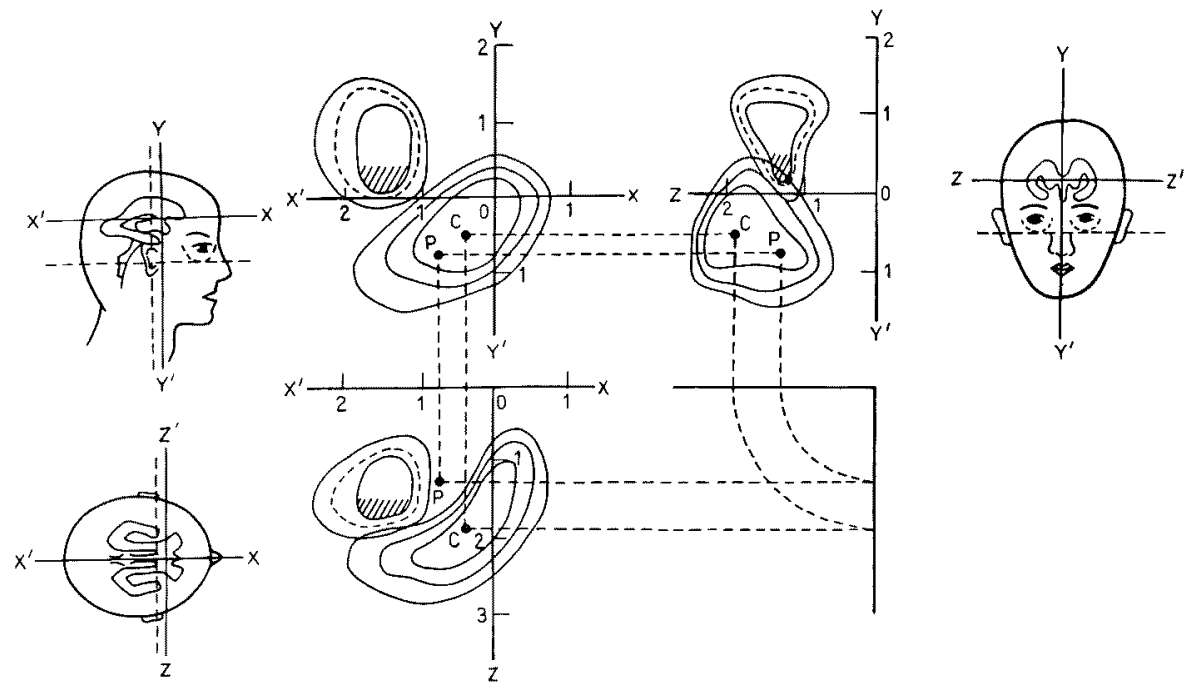

Fig. 13. Graphic representation of the pallidal globus and the lateral group of thalamic nuclei.

posterior to the foramen of Monro) and $15.0 \mathrm{~mm}$ in width $(9.0 \mathrm{~mm}$ and $24.0 \mathrm{~mm}$ lateral to mid-sagittal plane). These data are quite similar to those reported by Housepian and Carpenter (Fig. 13).

The angle formed by the axis of the pallidal globus and the mid-sagittal plane varied from 39 to 55 degrees and averaged 45 degrees, though 34 degrees (in those reported) by Housepian and Carpenter. It is interesting to note that the angle in the Japanese is about 10 degree greater than that in the Europeans.

It must be noted that the point (for instance, the point $P$ in Fig. 13), which would appear to be situated within the minimum composite pallidal zone in both the lateral and antero-posterior views, may actually be situated outside of the pallidal globus because of this obliquity of the axis of the mid-sagittal plane, and would theoretically present more chances of falling outside of pallidum in the Japanese than in the Europeans (Table 3).

As the lateral ( $\mathrm{Z}$ axis) and the antero-posterior ( $\mathrm{X}$ axis) distances from the foramen of Monro to the lesion are measured respectively in A-P and lateral views, it can easily be pointed out whether the lesion is within or outside of pallidum, when it is plotted on such a figure as shown in Fig. 14.

Thus the vertical projection in roentgenogram (submentovertical view) is not necessary for aiming at the pallidum.

2) Inclinations of the internal capsule to the mid-sagittal plane. The internal capsule is a broad structure separating the lentiform nucleus on the lateral side from the caudate nucleus and the thalamus on the medial side. It still remains to be question whether the pallidotomy or the thalamotomy in stereotaxic method, which in reality produce a blind lesion, is effective to Parkinsonism 
TABLE 3. Reporter

H. \& C.: Housepian, E.M. and Carpenter, M.B.

M. : Matsumoto, K. (author)

\begin{tabular}{|c|c|c|c|c|c|}
\hline & & \multicolumn{2}{|c|}{ Average } & \multirow{2}{*}{ Range } & \multirow{2}{*}{ Mean } \\
\hline & & $\mathrm{R}$ & L & & \\
\hline \multirow{2}{*}{$\begin{array}{l}\text { Distance from the midsagittal } \\
\text { plane to the medial border of } \\
\text { the pallidum (mm) }\end{array}$} & H. \& C. & 8.7 & 8.8 & $6-12$ & $9 \pm 1$ \\
\hline & $\mathbf{M}$ & 7.9 & 7.8 & $6-9$ & $8 \pm 1$ \\
\hline \multirow{2}{*}{$\begin{array}{l}\text { Distance from the midsagittal } \\
\text { plane to the lateral border of } \\
\text { the pallidum (mm) }\end{array}$} & H. \& C. & 25.7 & 25.7 & $23-28$ & $26 \pm 1$ \\
\hline & $\mathrm{M}$ & 26.8 & 26.6 & $24-28$ & $27 \pm 1$ \\
\hline \multirow{2}{*}{$\begin{array}{l}\text { Axis of the pallidum with res- } \\
\text { pect to the midsagittal plane } \\
\text { (degrees) }\end{array}$} & H. \& C. & 35.1 & 33.0 & $30-40$ & $34 \pm 1$ \\
\hline & $\mathrm{M}$ & 44.8 & 44.7 & $39-55$ & $45 \pm 1$ \\
\hline \multirow{2}{*}{$\begin{array}{l}\text { Dorsal extent of the globus } \\
\text { pallidus above the zero point } \\
(\mathrm{mm})\end{array}$} & H. \& C. & 8.9 & 8.7 & $7-11$ & $9 \pm 1$ \\
\hline & $\mathrm{M}$ & 3.3 & 3.0 & $1-5$ & $3 \pm 1$ \\
\hline \multirow{2}{*}{$\begin{array}{l}\text { Dorsal extent of the globus } \\
\text { pallidus below the zero point } \\
(\mathrm{mm})\end{array}$} & H. \& C. & 7.1 & 7.1 & $4-10$ & $7 \pm 1$ \\
\hline & $\mathrm{M}$ & 12.6 & 12.1 & $10-15$ & $12 \pm 1$ \\
\hline \multirow{2}{*}{$\begin{array}{l}\text { Over-all height of the globus } \\
\text { pallidus }(\mathrm{mm})\end{array}$} & H. \& C. & 16.0 & 15.8 & $15-19$ & $16 \pm 1$ \\
\hline & $\mathrm{M}$ & 16.0 & 15.1 & $13-18$ & $16 \pm 1$ \\
\hline \multirow{2}{*}{$\begin{array}{l}\text { Extent of the globus pallidus } \\
\text { rostral to the zero point (mm) }\end{array}$} & H. \& C. & 4.4 & 3.9 & $3-6$ & $4 \pm 1$ \\
\hline & $\mathrm{M}$ & 5.7 & 5.4 & $3-7$ & $5 \pm 1$ \\
\hline \multirow{2}{*}{$\begin{array}{l}\text { Extent of the globus pallidus } \\
\text { caudal to the zero point (mm) }\end{array}$} & H. \& C. & 17.1 & 18.9 & $14-23$ & $18 \pm 1$ \\
\hline & $\mathrm{M}$ & 15.2 & 15.4 & $11-10$ & $15 \pm 1$ \\
\hline \multirow{2}{*}{$\begin{array}{l}\text { Over-all length of the globus } \\
\text { pallidus (mm) }\end{array}$} & H. \& C. & 22.6 & 22.8 & $19-26$ & $22 \pm 1$ \\
\hline & $\mathrm{M}$ & 20.9 & 20.8 & 18.25 & $21 \pm 1$ \\
\hline
\end{tabular}

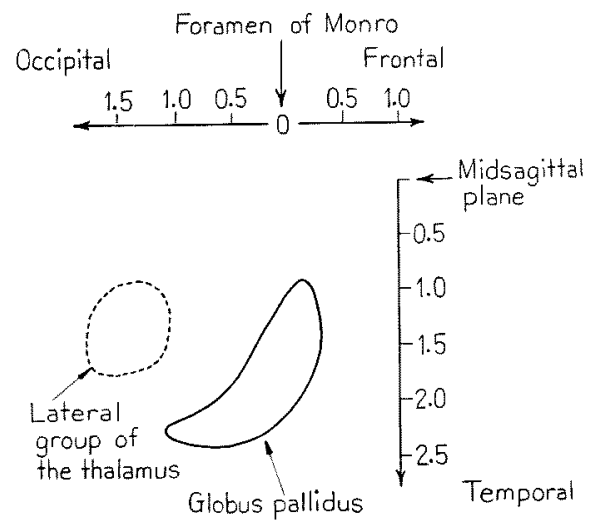

Fig. 14. Minimum composite zones of the globus pallidus and the lateral group of the thalamic nuclei in the dorsal projection (Y-axis). 
or other extrapyramidal disorders, or whether the lesion is only pallidal and thalamic or combined with the lesion on the internal capsule. From these points, the inclination of the internal capsule to the mid-sagittal plane was observed at the border line of the internal capsule and the pallidum (Fig. 15).

These inclinations are ranged from 23 to 42 degrees at various points of the internal capsule with individual variation of about 5 degrees and are largest $\left(42^{\circ}\right)$ at the point of $3-5 \mathrm{~mm}$ anterior to the foramen of Monro in all cases.

The standard curve is represented by a thick line and some of the most varied ones by a hair line in Fig. 15.

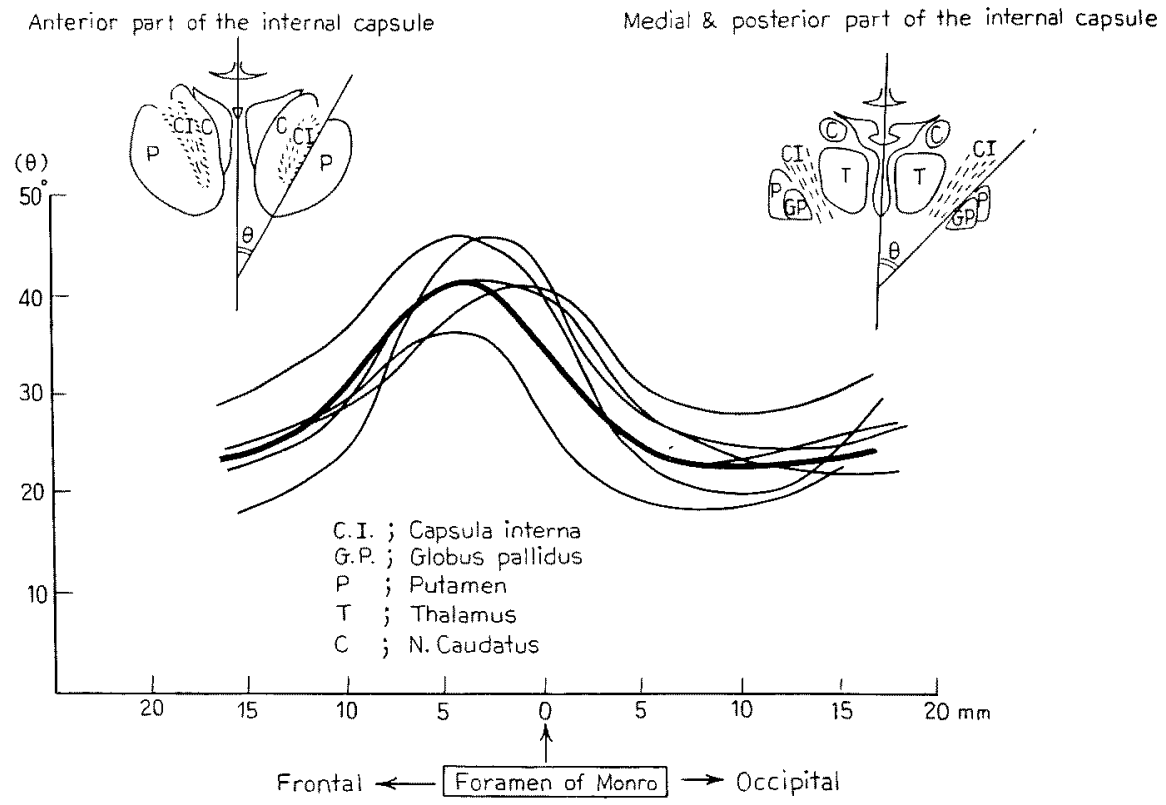

Fig. 15. Inclinations of the internal capsul to the mid-sagittal plane.

3 ) The site of the anterior commissure. The anterior commissure is situated in such a position as to have its center at the point about $3 \mathrm{~mm}$ anterior and inferior to the midpoint of the both foramina of Monro, and can be traced laterally and posteroinferiorly through the ventral part of the lentiform nucleus like a horseshoe. Its length is about $4 \mathrm{~cm}$, whose center can sometimes be identified in a satisfactory pneumoencephalogram. Therefore, Housepian and Carpenter or some of other neurosurgeons selected it to be the most reliable intracerebral reference point upon which the co-ordinate system is based for stereotaxic approach to the pallidal globus. However, it appears only in the satisfactory PEG, and thus the foramen of Monro, which is detectable in most of the cases, would seem to be more reliable reference point than the anterior commissure (Fig. 16). 


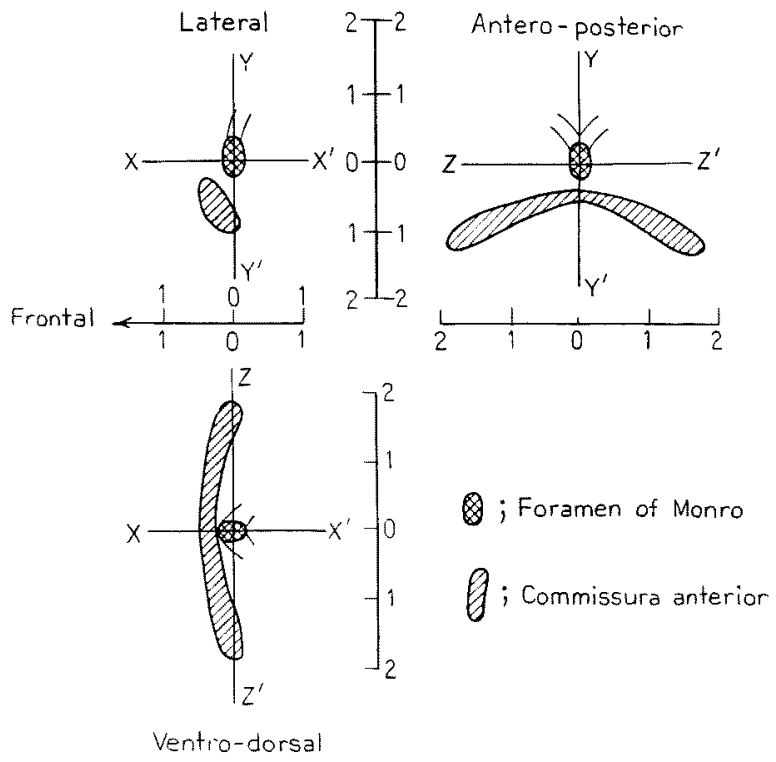

Fig. 16. The site of commissura anterior (schema).

4) The lateral group of the thalamic nuclei. In the stereotaxic surgery for extrapyramidal disorders, especially in Parkinsonism, the ventrolateral nucleus of the thalamus is aimed as a target as well as the pallidal globus. But this nucleus is hardly distinguishable in non-stained brain section, so that the whole lateral group of the thalamic nuclei was observed and registered in our three dimensional map.

As is case of the pallidal globus, area in the inner lips indicates the dimensions of the minimum composite zone, the middle line the mean composite zone, and the outer the maximum composite zone. But these are not so exactly compared with those of the pallidum because the border of the lateral group is not clearly distinguishable in some of non-stained sections.

The dotted line in Fig. 14 is a Y-axis (dorsal) projection of the lateral group of the thalamic nuclei, and its significance is the same as in the case of the pallidum.

5) The site of the red nucleus, substantia nigra and corpus Luysi. The position of the red nucleus ranges at $15 \mathrm{~mm}$ posterior, $6-8 \mathrm{~mm}$ lateral, $11-15 \mathrm{~mm}$ inferior to the foramen of Monro with less variation and that of the center of the substantia nigra is situated about $8 \mathrm{~mm}$ inferior to the center of the red nucleus, but the position of the corpus Luysi shows much more individual variations (Table 4). 
TABLE 4

\begin{tabular}{|c|c|c|c|c|c|c|c|}
\hline \multirow{2}{*}{ No. } & \multirow{2}{*}{$\begin{array}{l}\text { from } \\
\text { zero } \\
\text { point to }\end{array}$} & \multicolumn{2}{|c|}{ Copus Luysi } & \multicolumn{2}{|c|}{ Nucleus ruber } & \multicolumn{2}{|c|}{ Substantia nigra } \\
\hline & & $\mathbf{R}$ & L & $\mathbf{R}$ & $L$ & $\mathbf{R}$ & $L$ \\
\hline \multirow{3}{*}{$4 \mathrm{D}$} & below & & & $1.1 \sim 1.9$ & $1.0 \sim 1.9$ & $1.1 \sim 2.4$ & $1.2 \sim 1.4$ \\
\hline & lateral & & & $0.2 \sim 1.0$ & $0.2 \sim 1.0$ & $0.2 \sim 1.2$ & $0.2 \sim 1.2$ \\
\hline & posterior & & & $\sim 1.5 \sim$ & $\sim 1.5 \sim$ & $\sim 1.5 \sim$ & $\sim 1.5 \sim$ \\
\hline \multirow{3}{*}{$5 \mathrm{E}$} & below & $0.8 \sim 1.4$ & $1.1 \sim 1.6$ & $0.5 \sim 1.2$ & $0.6 \sim 1.3$ & $0.5 \sim 1.7$ & $0.7 \sim 1.3$ \\
\hline & lateral & $0.4 \sim 1.0$ & $0.4 \sim 1.0$ & $0.2 \sim 1.0$ & $0.1 \sim 0.8$ & $0.2 \sim 1.5$ & $0.2 \sim 1.6$ \\
\hline & posterior & $\sim 1.0 \sim$ & $\sim 1.0 \sim$ & $\sim 1.5 \sim$ & $\sim 1.5 \sim$ & $\sim 1.5 \sim$ & $\sim 1.5 \sim$ \\
\hline \multirow{3}{*}{$6 \mathrm{~F}$} & below & & & $0.9 \sim 2.0$ & $1.0 \sim 2.0$ & $0.9 \sim 2.5$ & $0.9 \sim 2.5$ \\
\hline & lateral & & & $0.2 \sim 0.9$ & $0.2 \sim 0.8$ & $0 \sim 1.4$ & $0 \sim 1.4$ \\
\hline & posterior & & & $\sim 1.5 \sim$ & $\sim 1.5 \sim$ & $\sim 1.5 \sim$ & $\sim 1.5 \sim$ \\
\hline \multirow{3}{*}{$7 \mathrm{G}$} & below & & & $1.5 \sim 2 \cdot 5$ & $1.5 \sim 2.5$ & $1.5 \sim 2.3$ & $1.5 \sim 2.3$ \\
\hline & lateral & & & $0.2 \sim 0.8$ & $0.2 \sim 0.8$ & $0.2 \sim 1.4$ & $0.2 \sim 1.4$ \\
\hline & posterior & & & $\sim 1.5 \sim$ & $\sim 1.5 \sim$ & $\sim 1.5 \sim$ & $\sim 1.5 \sim$ \\
\hline \multirow{3}{*}{$8 \mathrm{H}$} & below & $0.9 \sim 1.8$ & $0.8 \sim 1.6$ & $1.2 \sim 2.2$ & $1.0 \sim 2.0$ & $1.2 \sim 2.5$ & $1.0 \sim 2.5$ \\
\hline & lateral & $0.3 \sim 1.3$ & $0.3 \sim 1.1$ & $0.2 \sim 0.8$ & $0.2 \sim 0.8$ & $0 \sim 1.4$ & $0 \sim 1.3$ \\
\hline & posterior & $\sim 0.5 \sim$ & $\sim 0.5 \sim$ & $\sim 1.5 \sim$ & $\sim 1.5 \sim$ & $\sim 1.5 \sim$ & $\sim 1.5 \sim$ \\
\hline \multirow{3}{*}{91} & below & & & $1.0 \sim 1.8$ & $1.0 \sim 1.8$ & $1.5 \sim 2.4$ & $1.5 \sim 2.4$ \\
\hline & lateral & & & $0.2 \sim 0.8$ & $0.2 \sim 0.8$ & $0.2 \sim 1.0$ & $0.2 \sim 1.0$ \\
\hline & posterior & & & $\sim 1.5 \sim$ & $\sim 1.5 \sim$ & $\sim 1.5 \sim$ & $\sim 1.5 \sim$ \\
\hline \multirow{3}{*}{$10 \mathrm{~J}$} & below & & & $0.8 \sim 1.8$ & $0.8 \sim 1.8$ & $0.9 \sim 2.0$ & $1.0 \sim 2.0$ \\
\hline & lateral & & & $0.2 \sim 1.0$ & $0.2 \sim 1.0$ & $0.2 \sim 1.4$ & $0.2 \sim 1.2$ \\
\hline & posterior & & & $\sim 1.5 \sim$ & $\sim 1.5 \sim$ & $\sim 1.5 \sim$ & $\sim 1.5 \sim$ \\
\hline
\end{tabular}

The site of nucleus ruber \& sub. nigra

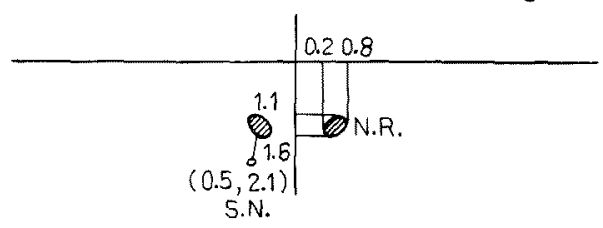

\section{SUMMARY}

The shape and spatial disposition of the pallidal globus, lateral group of the thalamic nuclei, the red nucleus, substantia nigra, corpus Luysi and anterior commissure with respect to the foramen of Monro and the inclination of the internal capsule to the midsagittal plane were investigated as a basic problem of the stereotaxic method.

The materials used in the present study consisted of 19 brains of the Japanese. The age of the patients ranged from 20 to 71 years and ten of the patients were male and nine were female. The cerebral hemisphres were cut in 
2-5 mm thick frontal sections by the brain-slicing macrotoms (author's own device).

1. A graphic method of representation was adopted for determining the size, shape and disposition of the pallidal globus and lateral group of the thalamic nuclei to facilitate our stereotaxic co-ordinate system.

2. The axis of the pallidum with respect to the mid-sagittal plane was about 45 degrees and was about 10 degrees greater than that reported by Housepian and Carpenter.

3. The position of the red nucleus had less individual variations as opposed to those of corpus Luysi.

4. Inclinations of the internal capsule to the mid-sagittal plane were greatest $\left(42^{\circ}\right)$ at the point $3-5 \mathrm{~mm}$ anterior to the foramen of Monro with individual variation of about 5 degrees in all cases.

\section{REFERENCES}

1) Higgins, J.W., MAHL, G.F., Delgado, J.M.R., and Hamlin, H.: Behavioral changes during intracerebral electrical stimulation, Arch. Neurol. Psychiat., Chicago, 76: 399-419, 1956.

2) DeLGado, J.M.R. and MiHAILovic, L.: Use of intracerebral electrode to evaluate drugs that act on the central nervous system, Ann. N.Y. Acad. Sci., 64, art. 4: 644-666, 1956.

3) JUNG, R. und RIECHERT, T.: Eine neure Methodik der operativen Elektrokortikographie und subkortikalen Elektrographie, Acta Neurochir. 2: 164-180, 1952.

4) JUNG, R. und RIECHERT, T.: EEG-befund bei Thalamusreizung am Menschen, Nervenarzt, 26: 35-40, 1955.

5) Cooper, I.S.: Clinical results and follow-up studies in a personal series of 300 operations for parkinsonism. St. Barnabas Symposium on Surgical Therapy of Extrapyramidal Disorders. P. 3-13, 1956.

6) SPIEgel, E. A. und Wycis H. T.: Ansotomy in paralysis agitans, Arch. Neurol. \& Psychiat., Chicago, 71 : 598-614, 1954.

7) SpIEgEL, E. A. and Wycis H. T.: The effect of thalamotomy and pallidotomy upon involuntary movements in chorea and athetosis, Surg. Forum, 329-332, 1951.

8) Cooper, I.S., Polaukhine, N. and HoEn, T.Z.: Chemopallidectomy for Dystonia musculorum deformans, St. Barnabas Symposium on Surgical Therapy of Extrapyramidal Disorders, P. 40-45, 1956.

9) NARABAYASH, H.: Procaine oil blocking of the globus pallidus for the treatment of rigidity and tremor of Parkinsonism. Psychiat. et Neurol. Japonica 56: 471-495, 1954.

10) Narabayashi, H., OKuma, T. and Shikiba, S.: Procaine oil blocking of the globus pallidus. Arch. Neurol. \& Psychiat., Chicago, 75: 36-48, 1956.

11) Jinna., D., Nishmoto, A., UMeda, A., Matsumoto, K.: Sterotaxic operation for involuntary moment and our apparatus (in Japanese). Operation, 13: 1-13, 1959.

12) Horsley, V. and ClaRE, R. H.: The structure and functions of the cerebellum examined by a new method. Brain $31: 45-124,1908$.

13) SpIeget, E. A., Wycrs, G. T., MARks, M. and LEE, A.J.: Stereotaxic apparatus for operation on the human brain. Science 106:349-350, 1947.

14) Austin, G.M. LEE, A.S.J., and Grant, F.C.: A new type of locally applied stereotaxic instrument. J. Amer. Med. Ass., 16: 147-148, 1956.

$$
-107-
$$


15) AUSTIN, G. and LEE, A.: A plastic ball and socket type of stereotaxic director. J. of Neurosurgery, 15: 264-268, 1958.

16) BAiley, P. and STEIN, S. N.: A stereotaxic apparatus for use on the human brain. Scientific Exhibit. A.M.A. Atlantic City, June 11-15, 1951.

17) JAsPER, H. and HUNTER, J.: A stereotaxic instrument for man. Electroenceph. clin, Neurophysiol., 1 : 533-536, 1949.

18) JAsper, H. and HunTER, J.: A stereotaxic instrument for man. Exhibited at meeting of Americen Electroencepalographic Soc. June 11-13, 1949. Atlantic City, N.J.

19) LEKSELL, L.: A stereotaxic apparatus for intracerebral surgery. Acta chir. scand, 99: 229-233, 1949.

20) LEKSELL, L.: Further note on a stereotaxic instrument for man. Kungl. Fusiografiska Sällskapets I Lund Förhandlinger 25: 138-141, 1955.

21) HAYNE, R., and MEYER, R.: An improved model of a human stereotaxic instrument. J. Neurosurg., 7: 463-466, 1950.

22) MARK, V.H., Mopherson, P.M. and SweET, W.H.: A new method for correcting distortion in cranial roentgenograms. With special reference to a new human stereotaxic instrument. Amer. J. Roentgenol., 71: 435-444, 1954.

23) Peutuiset, B.: Presentation d'un appareil stereotaxique adapte a l'homme. 14 Congres, Soc. Internat. de Chir. Paris, Sept. 28, 1951.

24) RiEcherT, T. und WoLfF, M.: Die technische Durchführung von gez. Hirnoperationen. Arch. Psych, u.z. Neurol. 190: 297-316, 1953.

25) SPIEger, E. A. and Wycls, H. T.: Stereoencephalotomy Part 1. Methods and Stereotaxic Atlas of the Human Brain Grune and Stratton, New York, 1952.

26) SPIEgel, E. A., Wycis H. T. and Goode, R.: A universal stereoencephalotome (model 5) for use in man and experimental animals. J. of Neurosurgery, 13: 305-309, 1956.

27) Talairach, J., AJURIaguerra, D. C. et DAvid, M.: Etudes stereotaxivues de structures encephaliques profundes ehez l'homme technique. La Presse Medicale no 28, 23 Avril, 1952.

28) Uchimura, Y., and NARABAYASH, H.: Stereotaxic instrument for operation on the basal ganglia. Psychiatria et Neurologia Japonica 52: 265-270, 1951.

29) Narabayashi, H.: Stereotaxic operation (2nd report)-Stereotaxic instrument for operation on the human basal ganglia. Pychiatria et Neurologia Japonica, 54: 669-671, 1953.

30) NARABAYASH, H. and OKuMA, T.: Stereotaxic operation (3rd report)-Procaine oil blocking of pallidum in the cases of athetose double Psychiatria et Neurologia Japonica, 54: 672-677, 1953.

31) FENELON, E.: Neurosurgical treatment of dyskinesias by a personal method: subpallidal extrapyramidectomy by electro-coagulation. Principles of the method, techniques, results and indication to surgery, Sem. Hop. Paris 28, 3775-3781, 1952.

32) FEnelon, F.: Neurosurgery of ansa lenticularis in dyskinesias and Parkinson's disease. Review of principles and techniques of a personal operation. Sem. Hop. Paris 31 : 18351955, 1955.

33) GuIoT, F. and BRION, S.: Treatment of choreoathetotic and parkinsonian syndromes. Sem. Hop. Paris 28: 2095-2099, 1952.

34) GuIot, G. and Brion, S.: Treatment of abnormal movements by pallidal coagulation; techniques and results, Rev. neurol. 89: 578-585, 1953.

35) Cooper, I.S. and Poloukhine, N.: Globus pallidus a surgical target, St. Barnabas Symposium on Surgical Therapy of Extrapyramidal Disorders. 14-39, 1956, J. Amer. Geriat. Soc., 4 : 1182-1207, 1956.

36) Cooper, I. S.: The Neurosurgical Alleviation of Parkinsonism, Charles C. Thomas, 1956.

37) BECKER, H. und RADTKE, F.: Eine Methode zur willkürlich steuerbaren Luftfüllung

$$
-108-
$$


der Ventrikel vzw. peripheren Liquorraume. Zugleich ein Beitrag zur Kenntnis des Ausbreitungsweges der Luft bei der Encephalographie, sowie der durch sie ausgelösten Reizerscheinungen, Nervenarzt $20: 442-448,1949$.

38) FLÜGEL, F.: Bemerkungen zur Luftenzephalographie, Zentralblatt für Neurochirurgie 3: $133-138,1955$.

39) Robertson, E. G.: Encephalography, Acta radiol., Stockholm, 34: 399-408, 1950.

40) LINDGREN, E.: Some aspects on the technique of encephalography, Acta radiol., Stockholm 31: 161-177, 1949.

41) DANDY, W.E.: Ventriculography following the injection of air in the cerebral ventricles, Ann. Surg. Phila., 68: 5-12, 1918; Localization or elimination of cerebral tumors by ventriculography, Surg. Gyn. Obst., 30:329-339, 1920; Localization brain tumours by cerebral pneumography, Am. Four. Rontgenol., 10:610-619, 1923.

42) DavidofF, L.M. and DyKe, C.G.: The normal encephalogram, Lea \& Febiger, Philadelphia 1951; DAvidofF, L.M. and EPSTEIN, B.S.: The abnormal pneumoencephalogram, Lea \& Febiger, Philadelphia 1955.

43) Robertson, J.S.: Some physical aspects of encephalography, Brain, 70:59-67, 1947.

44) Shapiro, R. and RABINSON, F.: Controlled pneumoencephalography, J. of Neurosurgery, 11 : 122-127, 1954.

45) BECkER, H. und RAthke, F.: Über eine neue encephalographische Methode, Hirnkammern und erweiterte periphere Spaltraume isoliert zur Darstellung zu bringen, Fortschr. Röntgenstr., 72: 160- , 1949.

46) Dyken, M.: Pneumoencephalography with direct injection and positional directing of air, J. of Neurosurgery, 16: 99-106, 1959.

47) Dandy, W. E.: Practice of surgery, W. F. Prior Company, 1953.

48) Twining, E. W.: Radiology of the third and fourth ventricles, The British Journal of Radiology, 12: 385-418, 569-600, 1939.

49) Lysholm, E.: Das Ventrikulogramm, Acta Radiol. Supplement 24, 25, 1937; Neurere Erfahrungen mit der Ventriculographie der 3 u. 4 Hirnkammer, Der Nervenarzt, 10: 1-13, 1937.

50) BaLAdo, M., Morea, and Donovan, C.: As radiografia del trecer ventriculo, Arch. Argent de Neurol., 237-245, 1927.

51) Housepian, E.M. and Carpenter, M. B.: Spatial relationships between the globus pallidus and the anterior commissure, J. Neurosurg. 14: 363-373, 1957. 